\title{
WestVirginiaUniversity
}

THE RESEARCH REPOSITORY @ WVU

Graduate Theses, Dissertations, and Problem Reports

2002

\section{Heart rate reactivity, aggression, anger, and antisocial behavior in dating males}

Jennifer L. Guriel

West Virginia University

Follow this and additional works at: https://researchrepository.wvu.edu/etd

\section{Recommended Citation}

Guriel, Jennifer L., "Heart rate reactivity, aggression, anger, and antisocial behavior in dating males" (2002). Graduate Theses, Dissertations, and Problem Reports. 866.

https://researchrepository.wvu.edu/etd/866

This Thesis is protected by copyright and/or related rights. It has been brought to you by the The Research Repository @ WVU with permission from the rights-holder(s). You are free to use this Thesis in any way that is permitted by the copyright and related rights legislation that applies to your use. For other uses you must obtain permission from the rights-holder(s) directly, unless additional rights are indicated by a Creative Commons license in the record and/ or on the work itself. This Thesis has been accepted for inclusion in WVU Graduate Theses, Dissertations, and Problem Reports collection by an authorized administrator of The Research Repository @ WVU. For more information, please contact researchrepository@mail.wvu.edu. 
Heart Rate Reactivity, Aggression, Anger, and Antisocial Behavior in Dating Males

\author{
Jennifer L. Guriel
}

Thesis submitted to the Eberly College of Arts and Sciences at West Virginia University in partial fulfillment of the requirements for the degree of

\author{
Master of Arts \\ in \\ Clinical Psychology
William Fremouw, Ph.D., Chair Kevin Larkin, Ph.D. Stan Cohen, Ph.D. \\ Department of Psychology \\ Morgantown, West Virginia \\ 2002
}

Keywords: Heart Rate Reactivity, Dating Violence 


\section{ABSTRACT \\ Heart Rate Reactivity, Aggression, Anger, and Antisocial Behavior in Dating Males}

\section{Jennifer L. Guriel}

This study assessed heart rate reactivity and antisocial characteristics, subjective report of anger, and family history variables in 18 aggressive and 18 nonaggressive undergraduate males in an attempt to test the generalizability of Gottman et al.'s (1995) investigation of cardiovascular reactivity as a typological variable for male batterers. Participants were categorized according to their scores on the Conflict Tactics Scale, Revised. Heart rate reactivity, personality variables (using the Minnesota Multiphasic Personality Inventory, Second Edition), and anger (using the State Trait Anger Expression Inventory) were subsequently measured during standardized interpersonal discussion tasks with a female confederate during the laboratory phase. Aggressive males reported having angrier temperaments and reactions to provocative situations than did their non-aggressive peers. Aggressive and non-aggressive males did not differ in terms of heart rate reactivity, personality variables, control or expression of anger, or witnessing violence between parents. 


\section{Acknowledgements}

I would like to thank all three members of my committee, William Fremouw, Ph.D., Kevin Larkin, Ph.D., and Stanley Cohen, Ph.D., for their persistent support, invaluable advice, and flexibility. This project would never have been possible without the time and effort that each contributed. I would like to express my deepest gratitude to Bill Fremouw for always encouraging me to push myself to be the best that I can be and for fostering creative ideas while maintaining a lighthearted attitude to make graduate school worthwhile. Sincere appreciation goes to Kevin Larkin for graciously allowing me to utilize his laboratory space and equipment for this project. Special thanks are extended to Stan Cohen for being a premiere statistical advisor, for this project and a host of other endeavors.

I am grateful to all of my helpful research assistants whose participation at various stages of this project was genuinely appreciated. Ashley Berger, Jenny Mankins, Julie McCarty, Kristy Matala and Jessica Richardson (in order of appearance) were all Oscar-deserving actresses and dependable helpers.

I would like to thank my loving family and friends for their support, encouragement, and reassurance throughout the course of this project and beyond. For their listening, commiserating, comic relief, and inspiration, I am infinitely appreciative. Finally, I would like to thank my fiancée, Ken, and my favorite little Shih Tzu, Buddy, for their patience and understanding and for keeping me sane when things did not go as well as expected. 
Table of Contents

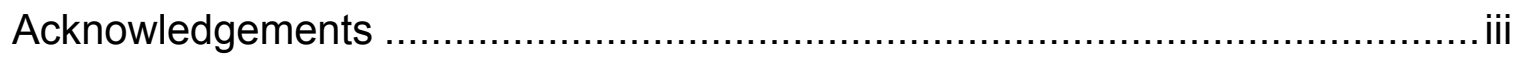

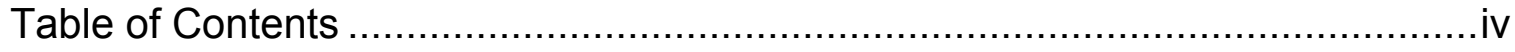

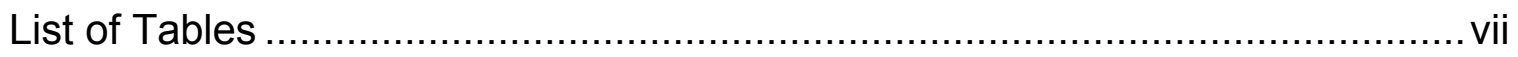

List of Appendices ….......................................................................... vii

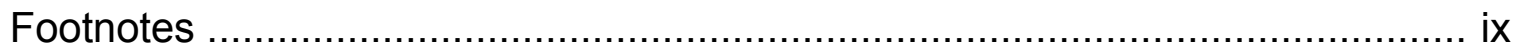

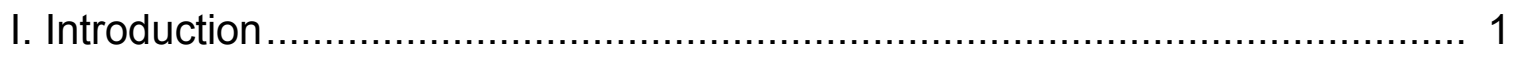

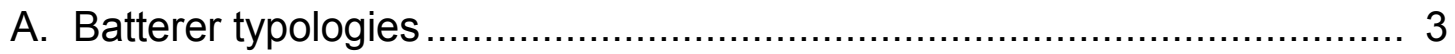

B. Heart rate reactivity in the stress response ....................................... 6

C. Heart rate reactivity and the experience of anger ................................ 8

D. Criticisms of Gottman et al. (1995) ................................................ 9

E. Statement of the problem........................................................... 14

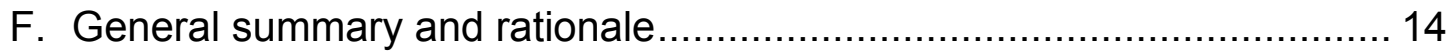

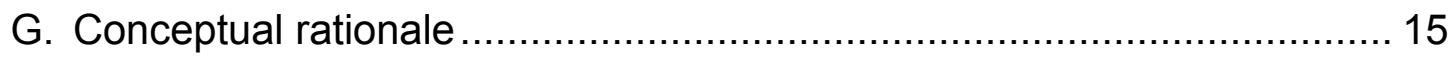

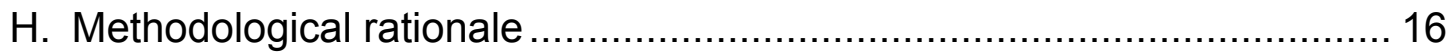

I. Specific Research hypotheses....................................................... 18

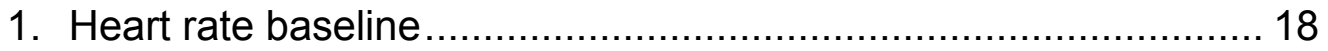

2. Heart rate reactivity (aggressive) …...................................... 18

3. Heart rate reactivity (control) …............................................... 19

4. Antisocial characteristics ....................................................... 19

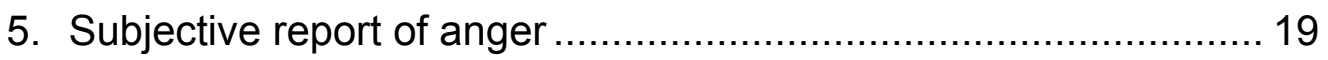

6. Exposure to interparental violence ............................................ 19 


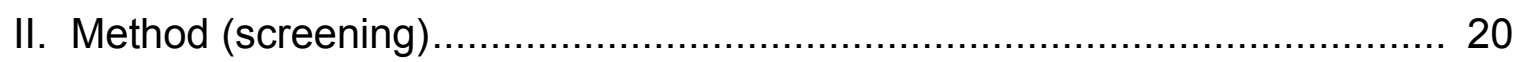

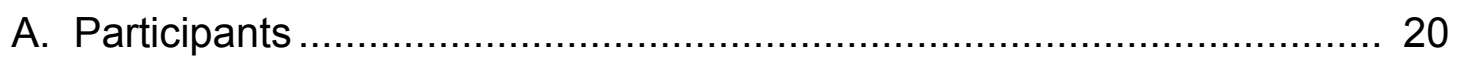

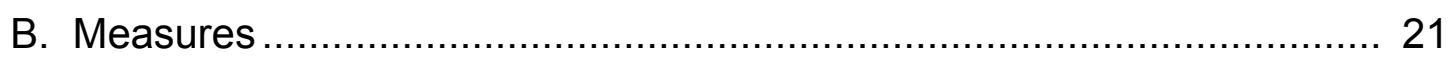

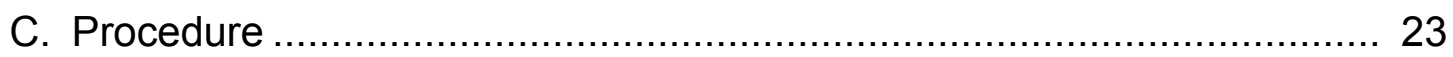

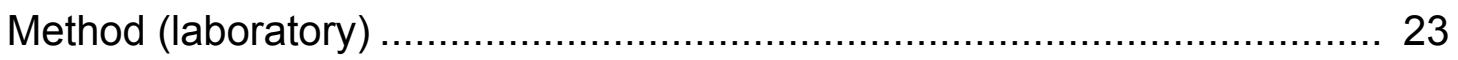

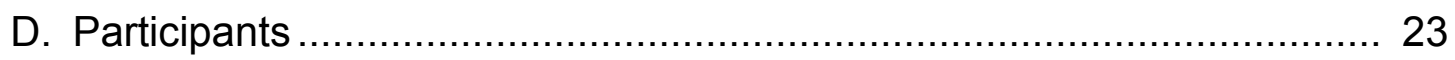

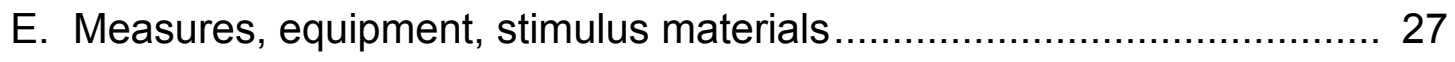

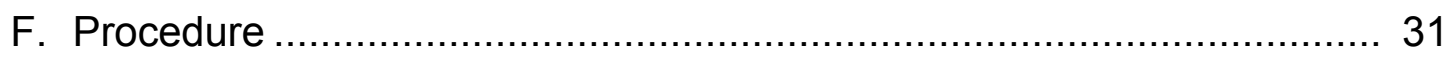

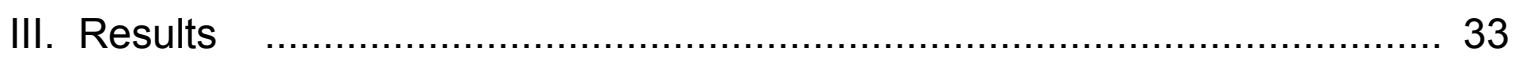

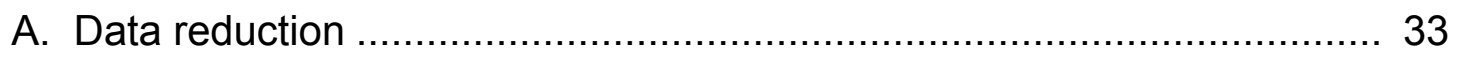

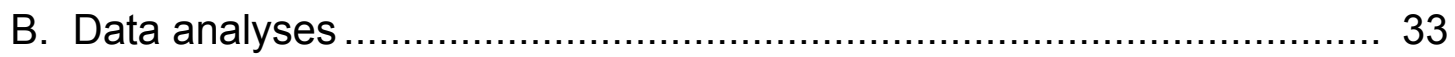

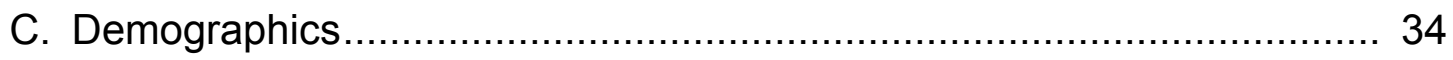

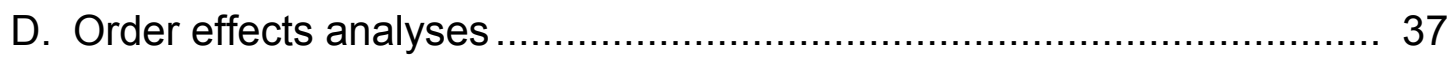

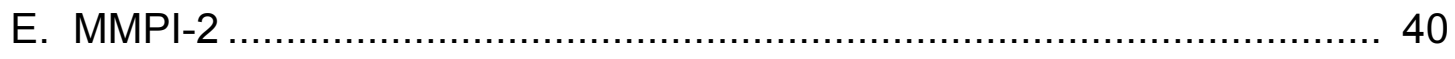

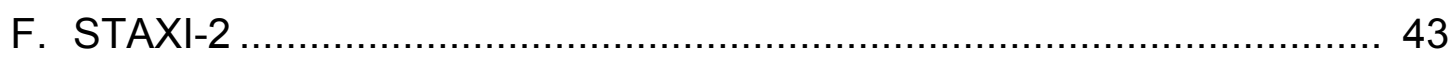

G. Heart rate (baselines included) …............................................ 47

$\mathrm{H}$. Heart rate (baselines as covariates) ……..................................... 49

I. Heart rate (extreme scores) …................................................... 51

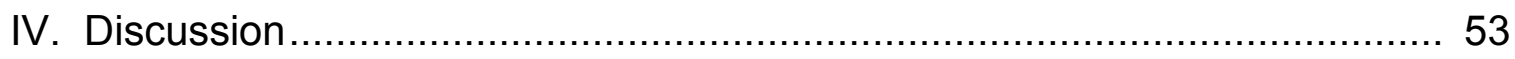

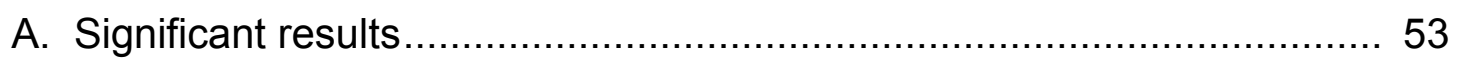

1. STAXI-2 Trait scale and subscales ...................................... 53

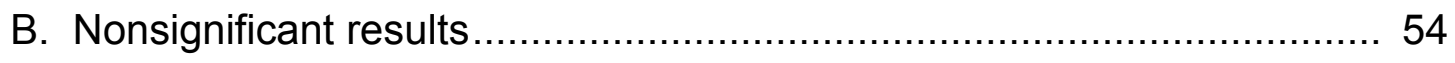

1. Demographic information ..................................................... 54 


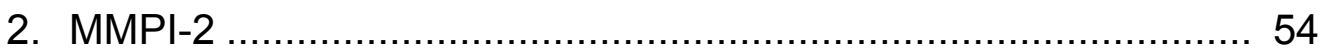

3. STAXI-2 Anger control and expression scale and subscales ....... 55

4. STAXI-2 State scale and subscales …………..................... 55

5. Heart rate (baselines included) …....................................... 56

6. Heart rate (baselines as covariates) ..................................... 57

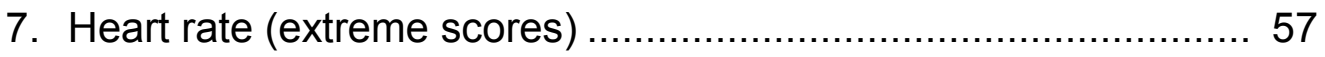

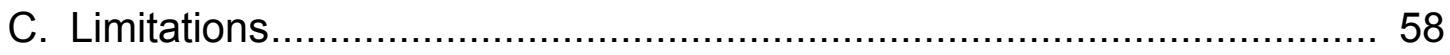

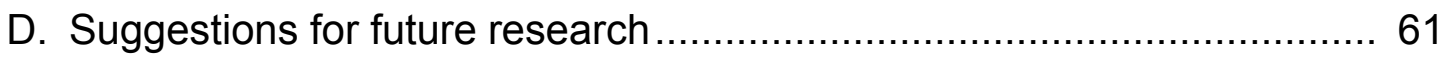

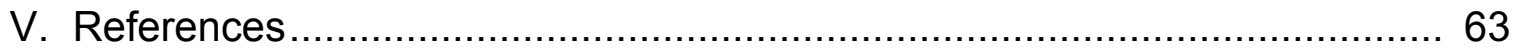


List of Tables

Table 1. Medical Conditions and Substances for Potential

Exclusion Criteria

Table 2. Demographic Characteristics, $X^{2}$ Values, and

F Values by Group

Table 3. Order Effects Analyses For Presentation of Discussion

Task Scenarios: Subjective and Objective Reports of

Arousal

Table 4. Minnesota Multiphasic Personality Inventory, second edition

T-scores, $\mathrm{F}$ Values, $\mathrm{n}^{2}$ Values, and Significance by

Group

Table 5. State Trait Anger Expression Inventory, Revised Scores, $n^{2}$ Values, $F$ Values, and Significance by Group

Table 6. Heart Rate Means, Standard Deviations, $n^{2}$ Values, F Values, and Significance by Group.

Table 7. Heart Rate Changes with Baselines as Covariates:

Change Scores, $\mathrm{n}^{2}$ Values, F Values, and Significance.

Table 8. Pearson Chi Square Analyses of Median Split Heart Rate Changes 


\section{List of Appendices}

Appendix A. Classification Criteria for Experimental Groups …...................... 70

Appendix B. Conflict Tactics Scale, Revised ............................................ 72

Appendix C. Demographic Questionnaire ………................................... 76

Appendix D. Participant Discussion Task Instructional Sets............................ 79

Appendix E. Confederate Discussion Task Instructional Sets ......................... 81

Appendix F. Confederate Reliability Rating Form ........................................ 83 


\section{List of Footnotes}

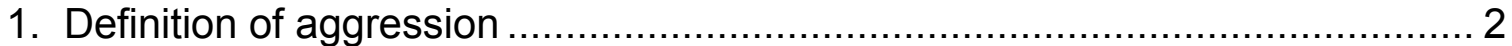

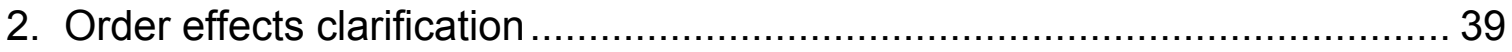


Heart Rate Reactivity, Aggression, Anger, and Antisocial Behavior in Dating Males

Intimate partner violence is a tremendous sociological problem in the United States. The U. S. Department of Justice statistics indicate that in 1998 approximately one million violent crimes were committed in which the perpetrator was a current or former spouse, boyfriend, or girlfriend of the victim (Bureau of Justice Statistics [BJS] Special Report, 2000). Previous epidemiological studies in the field of intimate partner violence, however, have estimated that partner violence is severely underreported, and consequently, that the base rate for such crimes is actually much higher (e.g., Straus \& Gelles, 1986). The present study attempted to assess the generalizability of a proposed physiological typology for perpetrators of intimate partner violence (Gottman et al., 1995). Gottman et al. identified a subgroup of men whose heart rates decreased in response to conflict discussions with their wives. This study attempted to identify similar patterns in a dating population.

Browne (1993) posited that as many as four million women may be severely assaulted each year. The latest report from the U. S. Department of Justice (BJS Special Report, 2000) also outlines that intimate partner violence accounted for $22 \%$ of all violent crime and $33 \%$ of all murders of females during a one-year period (1998-1999). In contrast, during this same year, intimate partners were responsible for only $3 \%$ of violence and $4 \%$ of murders of men (BJS Special Report). This implies that, although there is much evidence to support the hypothesis that women actually initiate an equal or greater amount of 
violence within intimate relationships compared to their male cohorts (Arias, Samios, \& O’Leary, 1987; Magdol et al., 1997; Riggs, O'Leary, \& Breslin, 1990), the violent acts of men tend to be more severe and have a more lasting impact (Arias \& Johnson, 1989; Jacobson et al., 1994).

Fortunately, over $65 \%$ of all violent incidents reported in the BJS study (2000) involving abuse perpetrated by both males and females were labeled as simple assaults. These incidents were characterized as acts in which the perpetrator did not use a weapon and where physical injury was minimal or absent (e.g., bruises, scratches, minor cuts, black eyes, etc.). Nevertheless, this implies that $35 \%$ of partner violence involves "violent" acts, defined by the Bureau of Justice Statistic's National Crime Victimization Survey (NCVS) to include murder, rape, sexual assault, and aggravated assault (characterized by use of or threat with a weapon), among others (BJS). ${ }^{1}$ Based on these statistics, it is evident that a thorough understanding of intimate violence as a phenomenon is essential to police, social workers, practitioners, and other professionals who may be called upon to develop preventative or treatment strategies for victims and perpetrators alike.

Despite the fact that partner violence has been a profound problem for centuries, it did not become the focus of research until the late 1970's and early 1980's (Straus, 1979; Straus, Gelles, and Steinmetz, 1980). Much of the early research involving intimate partner violence concentrated on domestic abuse, and more specifically, on incidents in which the husband was clearly the perpetrator and the wife was the victim. More recently, researchers have begun 
to recognize the importance of looking not only at abusive husbands, but also at dating couples who experience violence (Arias et al, 1987; Makepeace, 1981; Sugarman \& Hotaling, 1989) and at cases of female-initiated or mutuallyperpetrated violence (e.g., White \& Koss, 1991). Furthermore, recent studies have expanded the traditional notions of abuse as being characterized by only physical assault, and have begun to recognize the detrimental effects of psychological abuse as well (Kasian \& Painter, 1992; Murphy \& Hoover, 1999; O'Hearn \& Davis, 1997; Sackett \& Saunders, 1999; Tolman, 1999). Given this multidimensional nature of intimate partner violence, the need for typological categorizations is crucial to understanding who batterers are and what personal and environmental factors are associated with the perpetration of violent acts. Since this study utilized a recently proposed typology as a theoretical framework, a brief review of batterer typologies is warranted.

\section{Batterer Typologies}

Significant effort has been placed on identifying the specific factors associated with partner violence in an attempt to categorize batterers. Extensive research has led to the subsequent development of typological categorizations for abusive husbands (Hamberger \& Hastings, 1986; Holtzworth-Munroe \& Anglin, 1991; Saunders, 1992; Tweed \& Dutton, 1998). These typologies are similar in that each is trimodal and covers two primary dimensions relating to violent tendencies; control and impulsivity. In a meta-analysis by HoltzworthMunroe and Stuart (1994), for example, studies of both inductive and deductive theories of aggression in male batterers were reviewed and a typology was 
proposed in which batterers fell into one of three categories: family-only, dysphoric-borderline, and generally violent/antisocial. The family-only group confined their violence to intimate relationships and most resembled a nonviolent control group in terms of learning history when compared with the other battering subtypes. Family-only batterers, however, also had poor attachment, low levels of impulsivity, and some social skills deficits. Dysphoric-borderline batterers exhibited a significant history of abuse and parental rejection and were found to have high dependency on their wives, exacerbated by low interpersonal and social skills. Finally, the generally violent/antisocial group included individuals who had the greatest predisposition for aggression and who were violent outside the intimate relationship (e.g., they were more likely to be arrested for bar fights, etc.).

Although different terminology is used, several authors have proposed typologies that are very similar in topography of historical and personality factors (e.g., Hamberger \& Hastings, 1986; Saunders, 1992). Likewise, Tweed \& Dutton (1998) described three distinct groups of batters: instrumental/undercontrolled, impulsive/undercontrolled, and impulsive/overcontrolled. These three groups parallel those of Holtzworth-Munroe and Stuart (1994) (generally violent/antisocial, dysphoric/borderline, and family-only, respectively). In describing their typology, Tweed and Dutton emphasized the presence of a cyclical nature of violence in the impulsive groups, but a systematic use of violence for control and intimidation in the instrumental group. The verification 
that partner violence occurs in a cycle confirms what researchers have previously speculated.

Early paradigms of partner violence were based on the belief that all violent relationships were cyclical in nature with distinctive tension building, acutely violent, and contrition phases (Walker, 1984). The inclusion of the instrumental group, however, suggests that some perpetrators are not simply resorting to violence in reaction to stressors or increasing tension in the relationship, but are actually purposeful and may engage in abusive behavior, even if unprovoked. The men in Tweed \& Dutton's (1998) instrumental group, like those in Holtzworth-Munroe \& Stuart's (1994) generally violent group, scored higher on measures of antisocial personality characteristics and were violent outside of the intimate relationship as well.

Recently, Gottman and colleagues have proposed a novel typology for male batterers based on physiological markers (Berns, Jacobson, \& Gottman, 1999; Gottman et al., 1995) rather than historical or personality factors. In their groundbreaking study of physiological reactivity in a clinical sample of severe (based on Conflict Tactics Scale scores) male batterers, Gottman et al. compared the heart rate reactivity of 60 men during marital conflict discussions. Heart rate reactivity, in this study, was defined as the difference between the mean during the first 5 minutes of a dyadic discussion and the mean of the initial baseline. Their findings yielded two distinct subgroups of batterers: (1) those that displayed a decrease in cardiovascular activity during the conflict discussion (Type 1; approximately 20\%), and (2) those whose heart rate increased in 
response to the argument (Type 2; roughly $80 \%$ ). In addition, Type 1 men were more verbally aggressive, more generally aggressive (i.e., they engaged in higher rates of violence outside of the home), scored higher on measures of antisocial behavior, and scored lower on measures of dependency when compared to Type 2 batterers. Furthermore, Type 1 men reported witnessing significantly more interparental violence as children and scored higher on measures of anger than did Type 2 subjects.

These findings are important in the development of appropriate treatment programs for the heterogeneous battering population since most current intervention programs are targeted toward a homogeneous group (Malloy, McCloskey, and Monford, 1999). The overwhelming majority of current interventions are based on the assumption that excessive sympathetic arousal (i.e., increased heart rate, increased blood pressure, rise in blood glucose levels, release of epinephrine, etc.) is a risk factor for or is characteristic of battering. As a result, relaxation and anger management techniques are currently thought to be among the most beneficial behavioral treatment strategies. However, if batterers are physiologically different, perhaps other treatments would need to be developed.

\section{Heart Rate Reactivity in the Stress Response}

Cardiovascular reactivity has been operationally defined as individual variability in either heart rate or blood pressure that occurs in response to exposure to behavioral stimuli (Manuck, Kamarck, Kasprowicz, \& Waldstein, 1995). This variability is typically indicated by computing the difference between 
an individual's responding (heart rate or blood pressure) during baseline and exposure conditions (where behavioral stimuli are presented). Heart rate reactivity, in particular, has been shown to be the most stable indicator of cardiovascular reactivity over time and across contexts (correlation coefficients ranging as high as 0.91) (Manuck et al.). Given that heart rate is affected by the processing of all stimuli and that it is an involuntary physiological response, it can be classified as a trait, much like coordination, perception, or any other personal characteristics that are unique to an individual and relatively stable across covarying temporal and situational conditions.

Cardiovascular reactivity to stressful stimuli has been studied intensively (e.g., Krantz, Manuck, \& Wing, 1986; Smith, Gallo, Goble, Ngu, \& Stark, 1998). When examining reactivity to stressors, three general models are regularly employed: passive participation tasks (e.g., cold pressor paradigm, viewing film), mental challenge tasks (e.g., reaction time tests, mental arithmetic), and interpersonal interaction tasks (e.g., competitive games). Interpersonal stressors are seemingly the most generalizable to everyday behavior since they most resemble situations that participants are likely to engage in outside the laboratory setting. Larkin, Semenchuk, Frazier, Suchday, \& Taylor (1998) standardized two interpersonal challenge discussion tasks on a sample of undergraduate students for use in studying cardiovascular reactivity. Both are relevant to young adults and suitable for use with males and/or females. In one scenario an individual returns home to find an unkempt apartment that a roommate was asked to clean (the "mess" scene) and in the other an individual is forced to confront a neighbor 
who is playing loud music, which is interfering with his/her studying (the "noise" scene). Standardized confederate prompts are provided for each of these threeminute scenarios, aiding in practicality and convenience in research settings. These ("mess" and "noise") tasks were utilized for the laboratory phase of the current study. In addition to describing the involvement of heart rate reactivity in the stress response, a significant amount of research has focused on cardiovascular responding in the experience of anger.

\section{$\underline{\text { Heart Rate Reactivity and Experience of Anger }}$}

Correlations between the maladaptive effects of anger and the etiology of chronic, stress-related disease conditions are well documented in biopsychosocial literature. It is generally accepted that the repeated experience of anger can have a negative impact on an individual's physical health and psychological well-being (e.g., Spielberger and Sydeman, 1994). These negative effects are generally the result of excessive sympathetic activation, where increases in heart rate, respiration, cortical stimulation, and other "fight or flight" responses are experienced at high rates over a relatively long period of time. Research concentrated on identifying behavior motivated by anger became a major research topic during the 1970's with the introduction of the concept of the “Type A" behavior pattern (Friedman \& Rosenman, 1974).

The construct of anger has been traditionally difficult to define, but extensive research in this area by Spielberger, among others, has led to an understanding of the complex interaction of factors that comprise an anger response (or the lack thereof). In the late 1960's and early 1970's, Spielberger 
and colleagues began to develop a theory of anger as being an experience based on the interplay of both state and trait variables. They defined state anger as "a psychobiological state or condition consisting of subjective feelings of anger that vary in intensity, from mild irritation or annoyance, to intense fury and rage, with concomitant activation or arousal of the autonomic nervous system" and made the assumption that the experience of state anger would be dynamic and situation specific (Spielberger \& Sydeman, 1994). Trait anger was defined simply as "individual differences in the frequency that state anger was expressed over time" for any given individual (Spielberger, Ritterband, Sydeman, Reheiser, \& Unger, 1995; Spielberger \& Sydeman).

Given that cardiovascular reactivity is directly related to responding to stress and experiencing anger, it is commendable that Gottman et al. (1995) examined heart rate reactivity as a typological variable in male batterers. As with any preliminary investigation, though, conceptual and methodological rationale in the Gottman et al. study were critically scrutinized. Consequently, a clear need for replication and extension exists.

Criticisms of Gottman et al., (1995)

Although the preliminary Gottman et al. study (1995) introduced an innovative method to objectively classify intimate violent males, it was not without criticism. Margolin, Gordis, Oliver, and Raine (1995), for example, noted several problems with the methodology and conceptual rationale of the experiment. Specifically, Margolin et al. cited the discrepancy between the Gottman et al. findings and the available literature concerning resting and anticipatory heart 
rates in a criminal population. They pointed out that most theories of underarousal among criminals concern resting heart rates. Since there were no significant differences in resting heart rate between Type 1 and Type 2 men during Gottman et al.'s baseline condition ( $M=77.05 \mathrm{bpm}$; $S D=12.83)$, it is difficult to link the two areas of study as being parallel (Margolin et al.). In other words, existing literature on criminals who demonstrate physiological underarousal would predict that the participants in the Gottman et al. sample would have decreased baseline heart rates as opposed to decreased reactivities. Moreover, the Gottman et al. findings directly contradict some of the literature concerning anticipatory heart rate in psychopathic men. For instance, an increase in heart rate is associated with the anticipation of an aversive stimulus (Hare, Frazelle, \& Cox, 1978 as cited in Margolin et al., 1995), but Type 1 subjects in the Gottman et al. study had heart rate decreases. In general, an increase, not a decrease, in heart rate has been found to be directly associated with exposure to a stressor and would intuitively be the most likely response to a conflict discussion (e.g., Larkin et al., 1998). The reason for physiological response differences between Type 1 batterers and criminals, then, remains unclear.

Other areas of physiological investigation of aggressive populations are plagued by conflicting findings as well. It was found, for instance, that mothers determined to be at risk for abusing their children had more dramatic and more prolonged heart rate increases in response to laboratory stressors than did mothers who not considered to be at risk (Casanova, Domanic, McCanne, \& 
Milner, 1992). This indicates that a group of potentially abusive participants had larger increases in heart rate when presented with stressful challenges than did controls (i.e., those individuals determined to be at low risk for child abuse). Mezzacappa et al. (1997), on the other hand, found that adolescent males who had increased levels of antisocial/aggressive behavior (based on self-, teacher-, and maternal-reports) also had diminishing heart rates in laboratory measurements during two postural conditions whereas boys who were reportedly anxious (the other group in the study) had heart rate increases when changing postural conditions. Although it may appear that the findings of Mezzacappa et al. with antisocial/aggressive adolescents are closely related to those of Gottman et al. (1995) with male batterers, comparison is problematic since there was no dyadic interaction in the Mezzacappa et al. study. Therefore, the literature regarding potential physiological markers in criminal and abusive populations remains limited and inconsistent.

Another major criticism of the Gottman et al. (1995) Type 1/Type 2 categorization involves the baseline period and the operational definition of resting heart rate. First, it was speculated that the baseline period of two minutes was simply not long enough to obtain a true measure of resting heart rate (Margolin et al., 1995; Ornduff, Kelsey, \& O'Leary, 1995). This criticism is supported by the fact that Gottman et al.'s (1995) batterers had a mean resting heart rate of 77.05 beats per minute (bpm), which was not significantly different from Gottman's reported mean for adult males (76 bpm), but was different from the mean for adults males reported by a number of other investigators (70 bpm) 
(e.g., Larsen, Schneiderman \& Pasin, 1986). If it were the case that the males in the Gottman et al. study actually had elevated "resting" heart rates, then the decreases observed in the Type 1 men may simply have been habituation or return to baseline effects and may not represent a decreased heart rate reactivity. Finally, Margolin et al. (1995) question whether: (1) the Type 1 versus Type 2 categorization of batterers is unique to a sample of battering men, or is found, more generally, in a sample of distressed, yet nonviolent (e.g., those who engage in psychological, but not physical, abuse) or control (nondistressed, nonviolent) males? and (2) this response pattern is specific to a marital conflict discussion or is generalizable to a variety of stress-inducing stimuli? The current study will address each of these issues.

The current study had three broad purposes. First, it served as an attempt to assess the generalizability of the finding that male batterers are a heterogeneous group and can be categorized based on their heart rate reactivity. Undergraduate males who self-reported intimate partner aggression were further assessed to determine whether they would exhibit heart rate reactivity patterns similar to the clinical husbands in the Gottman et al. (1995) study. Secondly, the present study expanded the investigation into the dating population and included not only violent men, but also psychologically aggressive, but nonviolent and non-aggressive (control) males. These distinctions were made based on scores on the Conflict Tactics Scale, revised (Straus, Hamby, Boney-McCoy, \& Sugarman, 1996). It was the intention of the authors to compare three distinct experimental groups based on self-reported information regarding their dating 
behavior: (1) participants who engaged in physical violence toward their partner ("violent"), (2) those who engaged in psychological aggression (i.e., shouting, swearing, stomping out of the room), but abstained from physical aggression ("psychologically aggressive), and (3) those who were non-aggressive (i.e., not psychologically or physically violent) ("control"). Unfortunately, soliciting participants for these three groups was determined to be impractical after extensive screening of over 750 undergraduate students yielded very few (i.e., less than 10) participants who met the criteria for the violent group. In addition, participant attrition was a significant challenge with rates of participants who agreed to participate, but failed to report being as high as $75 \%$ at some points during the data collection period. As a result, the psychologically aggressive and violent participants were combined to create an "aggressive" group. This group was compared to the control group to yield a two-group comparison for data analytic purposes. A detailed explanation of how participants were categorized can be found in Appendix A.

Lastly, this study addressed some of the methodological criticisms of the Gottman et al. study (1995) by extending the time for the baseline period, including a control group to a serve as normative comparison for resting heart rate data, and using standardized social confrontation challenges with female confederates, rather than significant others, for discussion tasks. Extending the baseline from two (as in the Gottman et al. study) to ten minutes increased the probability of obtaining a true estimate of each participant's resting heart rate. By employing a control group design the criticisms of what value to use as an 
"average" adult male's resting heart rate was eliminated. Instead, the mean baseline heart rates of the control group could be compared to those of the aggressive group. Female confederates, rather than intimate partners, were used because recruiting dating couples to discuss actual relationship issues is not practical (e.g., many significant others do not live in close proximity to each other [particularly in college populations], anticipated funding is not such that all participants could be financially compensated, it is difficult to schedule two participants for each session, etc.). Furthermore, using confederate females, as opposed to significant others, permitted for further testing of the hypothesis that the pattern of decreasing heart rate reactivity (observed by Gottman et al.) is indeed a trait among some male batterers. If heart rate decelerators were found only during discussions with their significant other, their pattern would represent more of a state than a trait variable and would therefore be extremely difficult to target with prevention or intervention programs.

\section{Statement of the Problem}

\section{General Summary and Rationale}

During the past two decades, dating violence has emerged as an important research topic, separate from domestic abuse, and involving both males and females as perpetrators, victims, or both (Arias et al., 1987; Makepeace, 1981; Sugarman \& Hotaling, 1989). Although many studies have been conducted to characterize violent and/or victimized individuals within a dating context (Hamberger \& Hastings, 1986; Holtzworth-Munroe \& Anglin, 1991; Saunders, 1992; Tweed and Dutton, 1998), ambiguous or inconclusive data have 
prevented agreement on prevalence rates. Further, conflicting data exist regarding demographic variables, contextual factors, historical correlates, clinical variables, and interpersonal variables in creating a typology of batterers (Lewis \& Fremouw, 2001). To date, no studies have been conducted to investigate the role of physiological reactivity in a dating violent population.

Gottman et al. (1995) have recently taken a novel approach to developing a typology of male batterers by comparing and contrasting the heart rate reactivities of a clinical sample of severely violent, abusive husbands. Results of this study show that batterers form two groups based on physiological responding to (stressful) conflict discussion situations with their wives (Gottman et al.). Further investigation, however, has not been conducted to either replicate these findings in a domestic violent sample or to expand them into a dating violent sample. Logically, since heart rate reactivity is an inherent trait, if there are differences in the reactivities of male batterers, they should be found in all age groups and in dating as well as domestic violent relationships. Increased knowledge of this heterogeneous group and the complex interaction of variables that characterize them would be invaluable, not only for developing treatment and intervention programs, but may also serve as a tool in preventing violence in intimate relationships altogether.

\section{Conceptual Rationale for Current Study}

Most etiologic models of dating violence involve social learning (Bandura, $1965,1973)$ or similar imitative theories. Such hypotheses are often characterized primarily of subjective (e.g., self-report, etc.), rather than (typically 
more accurate) objective measures and rely on observational learning history for explanation of current behavior. Obvious problems exist with such models. First, as with any complex behavior, it is likely that more than one etiologic variable is involved in the development of interpersonal aggression among dating couples. If this is the case, then a one-dimensional model (e.g., social learning theory) could not possibly account for the entire etiologic profile. Secondly, based on prevalence rates for both dating violence and childhood witnessing of interparental aggression, it is clear that, even though perpetrators may have greater exposure to parental violence, not all children who see their parents engaging in violent acts exhibit abusive behavior as adults (e.g., Bernard \& Bernard, 1983). The current study attempts to expand the etiologic model of intimate violence by identifying another dimension of potential importance, physiological reactivity.

Methodological Rationale for Current Study

The current experiment is designed to be an assessment of the generalizability of the innovative physiological reactivity work done by Gottman et al. (1995). Although their findings created a maelstrom of both praise and controversy, few attempts to replicate have been made by interpartner aggression researchers. Moreover, the attempt to study this phenomenon within a dating aggressive (as opposed to a martially violent) sample population has not occurred. This is unfortunate, since early identification of risk factors for intimate abuse (physiological or otherwise) may be crucial in efforts to take a proactive, as opposed to reactive, stance in eliminating violent relationships. In addition, it is 
equally important to intervene in dating relationships before they become complicated by legal (e.g., marriage) and moral (e.g., having a child together) matters. It may be that the Gottman et al. study has not been replicated because it was conducted in conjunction with a number of other investigations of batterers and victims and was supported by a number of sizable grants. The measures employed were comprehensive, ambitious, and necessitated the involvement of a large number of researchers and assistants.

For the current study, alterations in heart rate between a resting (baseline) period and a discussion task were used as the index of physiological reactivity. This method is commonly employed in investigations of physiological responsiveness across contexts (Larkin et al., 1998; Smith \& Brown, 1991; Suls \& Wan, 1993). More specifically, confederate females were used to take part in dyadic interactions that were comprised of standardized social confrontation challenges (i.e., the "noise" and the "mess" scenes of Larkin et al., 1998). This utilization of an interpersonal conflict discussion is a basic paradigm in stress/cardiac reactivity research, similar to mental challenge tasks (e.g., mental arithmetic, mirror tracing, etc.) used with individual participants. The use of confederates, rather than intimate partners, also made practical sense because recruiting actual dating couples from a University sample with no financial incentive would be virtually impossible. A baseline, challenge, return to baseline, challenge $(A B A B)$ design was utilized for data collection and comparison of cardiovascular reactivity both between- and within-subjects in the current study. 


\section{Specific Research Hypotheses}

\section{$\underline{\text { Hypotheses Related to Physiological Measures }}$}

Heart rate baseline. No significant differences were expected between the two experimental groups (control and aggressive) during the 10-minute baseline period. It was believed that, since Gottman et al. (1995) found differences only in reactivity (and not in resting heart rates) all men should have similar resting heart rates. If, however, there were significant baseline differences between the control and the aggressive men, it was hypothesized that the physiological reactivities of the aggressive men would be similar to psychopathic or criminal male populations (i.e., their resting heart rates would be lower than those of the control males).

Heart rate reactivity in aggressive males. If Gottman et al.'s (1995) findings were generalizable, then there would be two subgroups of men within the aggressive group. The heart rates of one subgroup would decrease in response to a social confrontation interpersonal challenge (as did Gottman et al.'s Type 1 batterers), while the heart rates of the men in the other subgroup would increase when faced with a challenge from the confederate female (as did Gottman et al.'s Type 2 batterers). The percentage of heart rate decelerators to heart rate accelerators should then be approximately $20 \%$ to $80 \%$, respectively. It was acknowledged from the beginning, though, that the number of heart rate decelerators in this study may be even lower than what Gottman et al. found. This is due to having a relatively small sample of dating aggressive men $(n=18)$ and because it was hypothesized that these men may not be as severe in their 
violent behavior as Gottman's clinical group (particularly when the design had to be changed from a three- to two-group comparison).

Heart rate reactivity in non-aggressive (control) males. Based on evidence that heart rate reactivity is generally in the form of an increase when participants are presented with stressful stimuli, it was believed that the conflict discussions used in this study would elicit heart rate increases in the control individuals. $\underline{\text { Hypotheses Related to Self-Report Instruments }}$

Antisocial personality characteristics (as measured by the MMPI-2). Scale 4 of the MMPI-2 was empirically derived from a sample of young adults (primarily men) who were diagnosed as being psychopathic and/or amoral who had engaged in chronic, minor delinquency (Greene, 2000). As such, scale 4 elevations are typically associated with the behavior patterns of social maladjustment and impulse control, among others. It was hypothesized that males who were categorized as being aggressive in their intimate relationships would have the greatest number of elevations on scale 4, reflecting a higher incidence of antisocial behavior in this group than in the other two groups.

Subjective report of anger (as measured by the STAXI). Aggressive men were expected to score higher on measures of trait anger and anger expression than their non-aggressive peers. This would indicate that the aggressive males were generally angrier and more likely to overtly exhibit their anger than were non-aggressive males.

History of exposure to inter-parental violence (as measured by the demographic questionnaire). Based, in part, on modeling theories such as 
Bandura's social learning theory (Bandura, 1965, 1973), it was hypothesized that more men in the aggressive group would report witnessing inter-parental violence (particularly physical) when compared to the non-aggressive males. If a subgroup of the aggressive males in this study were similar to those in Gottman et al.'s (1995) Type 1 sample, then they were expected to report significantly higher rates of witnessing inter-parental violence as children than their peers.

Method

\section{Screening Phase (Phase 1)}

\section{$\underline{\text { Participants }}$}

Approximately 750 undergraduate males enrolled in psychology courses at West Virginia University participated in this phase of the study. To qualify for this research, men must have been involved in a heterosexual romantic relationship of at least three months duration at any time since age 15. Homosexual relationships were excluded from the current study, not because they are not of importance, but to maintain simplicity of design and eliminate confounding variables. Men who endorsed having at least one heterosexual romantic relationship lasting a minimum of three months were asked to answer questions concerning their "most serious" relationship. These criteria were used for two reasons. First, it is common for males to be involved in a number of shortlived relationships between the ages of 15 and 24 (the average age in our study was expected to be approximately 20 since all participants were undergraduate students and many were freshmen) and it was believed that it would be extremely difficult to find only those who were currently involved in relationships 
(particularly those that are aggressive). Secondly, the measure of interest, heart rate reactivity, is a trait (as opposed to a more dynamic state) variable so it should be consistent across temporal and environmental contexts.

\section{Measures}

Conflict Tactics Scale, revised (CTS 2). The CTS 2 (Straus et al., 1996) is a 78-item modification of the original Conflict Tactics Scale (CTS) (Straus, 1979). The CTS 2 requires subjects to rate the frequency of psychological and physical behavior that partners engage in along with their use of reasoning or negotiation strategies on an eight-point scale. The original CTS is the hallmark instrument used for classifying batterers in domestic and dating violence research. Although several investigators have used the CTS and found it to be psychometrically sound, it can be misleading to make direct comparisons of various studies because different scoring methods or cutoffs are often employed. Criticisms of the original CTS included brevity, awkwardness of format, weak distinction between minor and major violence, and hierarchical order of socially desirable items. The CTS 2 accounts for each of these criticisms by adding items, modifying existing items, randomizing the order of item presentation, and simplifying the format (See Appendix B). These changes were made while maintaining the theoretical focus that conflict is normative, but that violence is not (Straus et al, 1996).

Demographic Questionnaire. Information obtained from the demographic questionnaire included age, race/ethnicity, status and duration of most serious 
relationship, questions pertaining to previous exposure to parental violence, and an index of aggressive behavior outside the relationship context. Given the physiological measures utilized during the laboratory phase, questions pertaining to personal and familial heath issues were asked to avoid potential confounding variables. The demographic questionnaire also served as the means for recruiting subjects for Phase 2 (the laboratory phase) by allowing individuals to provide their name, phone number, and electronic mail (email) address to indicate willingness to participate in further investigation. See Appendix C. Classification of Experimental Groups. Based on CTS-2 scores, participants were classified as being either: (1) aggressive, or (2) non-aggressive. The aggressive group included those who reported engaging in psychological abuse (e.g., yelling/swearing at their partner, stomping out of the room following a dispute, etc.) or physical abuse (e.g., slapping, punching, kicking their partner). The majority of individuals within the aggressive group did not report severe or consistent episodes of physical abuse (e.g., they punched only once, or did not endorse the most severe items such as beating their partner up). In order to be categorized as a control (non-aggressive) participant, males could report only minor psychological aggression (e.g., swearing at their partner less than five times) and were required to have total absence of physical abuse in their most serious relationship. See Appendix A for a detailed presentation of classification criteria. 


\section{Procedure}

Participants were first required to give informed consent after being told that their participation was completely voluntary and that they had the right to withdraw at any time during the session without penalty. Participants were instructed to answer CTS-2 questions respective to their most serious relationship. This allowed for: (1) inclusion of participants not currently involved in a romantic relationship, and (2) a (theoretically) decrease in social desirability pressures associated with such a face-valid index of generally undesirable behaviors. The time frame utilized when responding to CTS-2 questions was, therefore, the duration of the most serious relationship. After completing the Conflict Tactics Scale, Revised (CTS 2) and the demographic questionnaire participants were asked to indicate their willingness to participate in Phase 2 of the study by providing their name and telephone number or email address on the Demographic questionnaire. This initial session required approximately 15 minutes for completion and recruitment was conducted in undergraduate psychology classes at West Virginia University.

\section{Laboratory Procedure (Phase 2)}

\section{$\underline{\text { Participants }}$}

Qualified men who expressed an interest in participation in the laboratory phase were called to participate in Phase 2 of the study. Although approximately 750 men were screened and at least 300 were contacted, only forty actually agreed to participate and followed through by attending their scheduled session 
(up to $75 \%$ agreed, but failed to attend the laboratory session). Four participants had unusable heart rate data due to equipment problems. The final number of participants for the laboratory phase was $36(n=18$ control and $n=18$ aggressive). Of these 36 males, only five reported physical violence in their dating relationship.

Some of the participants utilized an internet-based sign-up sheet to schedule their participation times. The majority, however were called by the primary investigator for scheduling. All participants were given reminder calls the night before their scheduled appointments. Initially, it was planned that those participants who reported chronic medical conditions or who reported taking medications that might interfere with cardiac functioning (See Table 1 for a list of example exclusionary medications and conditions) would be excluded from the study. Given difficulties in subject recruitment, however, all willing participants were permitted to participate in the laboratory phase of the study. This involved including males with current or historical morbidity (primarily asthma), but did not involve anyone taking medications or other substances that can interfere with heart rate measurements.

Statistical analyses determined that those who endorsed potentially exclusionary medical/health variables did not exhibit heart rate reactivities different from those who did not, regardless of their experimental group (i.e., control or aggressive). Therefore, all willing participants were utilized for the laboratory phase. Those who agreed to come into the laboratory were instructed to avoid eating, using tobacco, drinking beverages (other than water), exercising, 
or ingesting any drug/medication for at least two hours prior to their scheduled time. Participants completed a screening questionnaire to ensure that these instructions had been followed as part of the informed consent process of the laboratory phase. This decreased the probability that extraneous variables were spuriously affecting heart rate data. Despite including all willing participants, there was still a relative lack of statistical power for subsequent analyses given the small overall sample size $(n=36)$. 
Table 1

Medical Conditions and Substances for Potential Exclusion Criteria

\begin{tabular}{|c|c|c|}
\hline Morbidity & Medication & Substance \\
\hline History of CVA & Stimulants & Ephedrine/Guaranara \\
\hline History of $\mathrm{MCl}$ & Beta blockers & Caffeine (within 2 hrs of study) \\
\hline Hyperthyroidism & Anti-histamines & Anabolic Steroids \\
\hline Hypothyroidism & Benzodiazepines & Nicotine (within 2 hrs of study) \\
\hline Arrhythmia & Narcotics & \\
\hline Tachycardia & Psychotropics & \\
\hline High blood pressure & Anticoagulants & \\
\hline Atrial fibrillation & Lithium & \\
\hline Asthma & Steroid drugs & \\
\hline $\begin{array}{l}\text { Diagnosed Mental } \\
\text { Illness }\end{array}$ & Anticholinergics & \\
\hline $\begin{array}{l}\text { Childhood conditions } \\
\text { requiring continued } \\
\text { medical attention }\end{array}$ & Antidepressants & \\
\hline
\end{tabular}

Note: CVA = Cerebrovascular Accident. $\mathrm{MCI}=$ Myocardial Infarction. 


\section{Measures/Equipment/Stimulus Material}

Minnesota Multiphasic Personality Inventory, Second Edition (MMPI-2).

The MMPI-2 is a 567-item objective personality inventory designed to obtain basic information regarding a person's general beliefs, tendencies, and traits (i.e., groups of behaviors that are similar in various situations or contexts) (Butcher, Dahlstrom, Graham, Tellegen, \& Kaemmer, 1989). As a general rule, T-scores on the MMPI-2 have a mean of 50 and a standard deviation of $10 . \mathrm{T}$ scores above 65 are considered clinically significant, and those between 50 and 65 are said to be average to moderately elevated on the MMPI-2. The MMPI-2 consists of ten basic clinical scales, three standard validity scales, and a number of content, supplementary, and additional validity scales. The ten basic clinical and three standard validity clinical scales have been well researched and are psychometrically sound. The others, however, have not been studied as intensively, and should be interpreted more cautiously. Only the basic clinical and standard validity scales (370 items) were evaluated for participants in the present study. Elevations on scale 4 (Psychopathic deviate [Pd]) were used to assess antisocial characteristics of participants. Data from supplementary, content, and other scales was collected for use in a separate analysis.

State Trait Anger Expression Inventory, Second Edition (STAXI-2). The State-Trait Anger Expression Inventory (STAXI) was created in an attempt to assess an individual's experience of anger, disposition to experience anger, and ways in which anger is expressed using a brief, self-report instrument (Spielberger, 1998). The development of the STAXI was methodical and 
extensive, with the final version being a combination of two different measures (also created by Spielberger): the State-Trait Anger Scale, which measured anger experience (i.e., state variables such as feelings, and thoughts of verbal and physical anger) and disposition (i.e., trait variables such as temperament and reaction), and the Anger Expression Scale, which measured ways in which a person's anger could be expressed (e.g., control or lack of control over angry impulses, suppression of anger feelings).

Both the State-Trait Anger Scale and the Anger Expression Scale are comprised of several factors and have high alpha coefficients (e.g., .89, .90 and higher). The STAXI, comprised of five scales and two subscales, has seven factors from 44 items (Forgays, Forgays, \& Spielberger, 1997). The revised STAXI-2 (1998) is a 57-item instrument with six major scales and five subscales that is designed to measure an individual's experience, expression, and control of anger. It was revised on the basis of a number of empirical studies focused on the original STAXI. The STAXI-2, like its predecessor, uses a 4-point response scale $(1=$ not at all to $4=$ very much so). Preliminary psychometric data for the STAXI-2 show that alpha values range from .72 to .94 for scales and subscales (Spielberger). All STAXI-2 scales and subscales were evaluated for participants in this study. STAXI data provided an index of participants' anger tendencies and allowed for comparison of subjective (STAXI) and objective (heart rate) levels of arousal to conflict discussions.

Heart rate reactivity. Heart rate reactivity was measured using a Polar Vantage XL mobile heart rate monitor. This device includes a chest strap, which 
the participants placed under their shirts to detect heartbeat via electrodes, and a watch-like recording device that kept the time and continuously recorded data in five-second intervals during the laboratory phase. After the session was over, data was downloaded to a computer file via a Polar interface and accompanying software. The reliability of the Polar monitor has been demonstrated by Goodie, Schauss, Larkin, and Aragona (1997). Heart rate reactivity was defined as the change, in bpm, between a participant's mean heart rate during the baseline and his mean heart rate during challenge conditions (first from initial baseline to discussion 1, then from return to baseline to discussion 2). Since the discussion tasks lasted for three minutes each, baselines were calculated to be the mean of the last three minutes of the baseline period that the participant was not in the room with the confederate. Since the participant and confederate were in the room together, but not yet engaged in the discussion task, for the period of time that the directions were being played via audiotape, this time was eliminated from the baseline calculation. This was done to reduce spurious increases in heart rate caused simply by being in a novel situation with a stranger. Based on Larkin et al.'s (1998) standardization of interpersonal social confrontation challenge scenes, an average of an eight or more beat per minute (bpm) change was expected for the participants. This was expected to be in the positive direction for most participants, but was predicted to be negative for a subgroup of the aggressive group (similar to Gottman et al.' [1995] Type 1 men). Eight beats per minute is based on the standard deviations for the "noise" and the "mess" scenes in the standardization study ( $S D=7.79$ and $S D=9.17$, respectively). Fluctuations 
of less than eight bpm may not necessarily be of clinical significance since everyone has some level of fluctuation in physiologic responses such as cardiovascular reactivity.

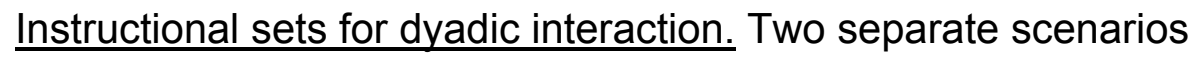
were used as discussion tasks in the experiment: the "noise" scene and the "mess" scene. These scenes have been standardized as protocols for evaluating cardiovascular reactivity via interpersonal conflict in a population of undergraduate students (Larkin et al., 1998). See Appendices D and E for a detailed description of these scenes. Scenes were practiced until the confederates had acceptable reliability, defined as at least $90 \%$ agreement by three observers who were unaware of the categorization of the male (aggressive or non-aggressive). Discussion tasks between each female condfederate and participants were videotaped. Observers lacking knowledge of the study then watched the videotapes and completed five questions regarding the female's performance using a Likert-type rating scale. See Appendix F. Observers had at least $90 \%$ agreement in rating questions 1,2 , and 4 , as either four or five and questions 3 and 5 as either 0 or 1 . This indicated that the confederate female was antagonistic, confrontational and relentless in the discussion and not friendly or compassionate. Three different observers rated each of five confederates (utilized at different times in the data collection) for a total of 15 independent ratings throughout the course of the study. 
Heart Rate Reactivity 31

\section{Procedure}

Participants in the laboratory phase were informed that participation was voluntary and that they had the right to withdraw at any time (while still receiving extra credit points and being entered into a cash-prize lottery). They were seated in a room containing a table, two chairs, an audiocassette player, and a video camera. After informed consent was obtained, participants were introduced to the heart rate apparatus by the primary investigator. Once a reading was established, the initial baseline recording began. It was explained to participants that they would be joined by a female for a "role-play" discussion following the 10-minute baseline period and that this dyadic interaction would be repeated (with a different topic) following a second baseline period. During the first baseline participants completed the STAXI trait and control scales. At the end of the initial baseline period (10 minutes) the confederate female was brought into the room. The confederate wore the wrist portion of the Polar monitor to give the impression that she was a participant in the study and had been going through the same procedure as the participant, but in a different location. Once they were seated diagonally from each other, the participant was given a brief description of the scenario and the confederate female was given a list of the standardized responses for that scenario. Both the participant and confederate then listened to an audio-recorded instructional set (including explanation that the dyadic interaction would be videotaped). Video data was used for rating confederate reliability only. The conflict discussion began and ended according to the 
recorded instructions. The duration of the discussion was three minutes (timing began after the dyad initially engaged in conversation).

Following the discussion task, the confederate and participant were separated and the participant completed the state form of the STAXI. Timing of the second baseline (return to baseline) began at the end of the first discussion task. The second baseline and discussion task were identical to the first, with the exception of the scenario used. The same confederate participated in both discussion tasks. Whichever scenario had not been used in the first discussion task was utilized for the second. Again, participants completed the STAXI state scale following the second discussion. This allowed for repeated measures comparisons of subjective reports of arousal. Subsequent analysis also relied on this information to ensure that participants did not differentially respond to the two scenarios (i.e., always rate the noise scene higher than the mess or the first scene higher than the second, etcetera). The order of the two scenarios (i.e., the "noise" and "mess" scenes) was counterbalanced to ensure that an equal number of individuals in each of the experimental groups received each scene first to avoid order effects.

Following the second discussion task, the Polar apparatus was removed and the participant was debriefed by the confederate (to explain her involvement in the study). After debriefing, $50 \%$ of the men completed the MMPI-2. The other half of the participants completed the MMPI-2 after giving informed consent, but prior to the physiological recording period. This was done for scheduling purposes and did not impact the results since counterbalancing techniques were 
employed. After all data had been collected, four participants were randomly selected to receive a $\$ 20.00$ cash prize for their participation.

\section{Results}

\section{Data Reduction}

Baseline heart rate data was reduced by averaging each participant's bpm across the last three minutes that the confederate was not in the room of the initial baseline and return to baseline conditions. To reduce heart rate data during challenge tasks, averages across each three-minute discussion were calculated for each individual. Individual means for baseline 1, interaction 1, change (from baseline to interaction) 1 , baseline 2 , interaction 2 , and change 2 were then compiled into a single data file for subsequent analyses. Change scores were used as the indices of heart rate reactivity.

\section{Data analysis}

Dependent variables including subjective report of anger following challenge tasks (STAXI State scale), antisocial tendencies on the MMPI-2, and demographic characteristics were analyzed using one-way analyses of variance (ANOVAs) or Pearson's Chi square (for categorical data). Although without any missing data the samples of aggressive and non-aggressive men were equal ( $n=18)$, the general linear model was employed to control for unequal group sizes. This prevented (rare) missing data from affecting the statistical analyses. Heart rate reactivities were analyzed by simple comparison (using one-way ANOVAs) and with the baseline periods removed (using one-way analyses of 
covariance [ANCOVAs]) with the baseline periods serving as covariates. An alpha level of .05 was used to evaluate all statistical analyses. Eta ${ }^{2}$ values were also obtained to provide an estimate of effect size.

\section{Demographic Variables.}

To determine whether the aggressive and non-aggressive males differed in terms of demographic variables, Pearson's $\mathrm{Chi}^{2}$ tests were performed for all categorical variables and one-way analyses of variance (ANOVAs) were utilized for variables with continuous data. Since a multiple-choice format was used and most answers were recoded into numerical variables, only three items were comprised of continuous data ("age", "length of most serious relationship", and "age during most serious relationship"). No omnibus differences were found between the aggressive and non-aggressive (control) groups for any of the demographic variables. See Table 2. 
Table 2

Demographic Characteristics, $\mathrm{X}^{2}$ Values, and F Values by Group

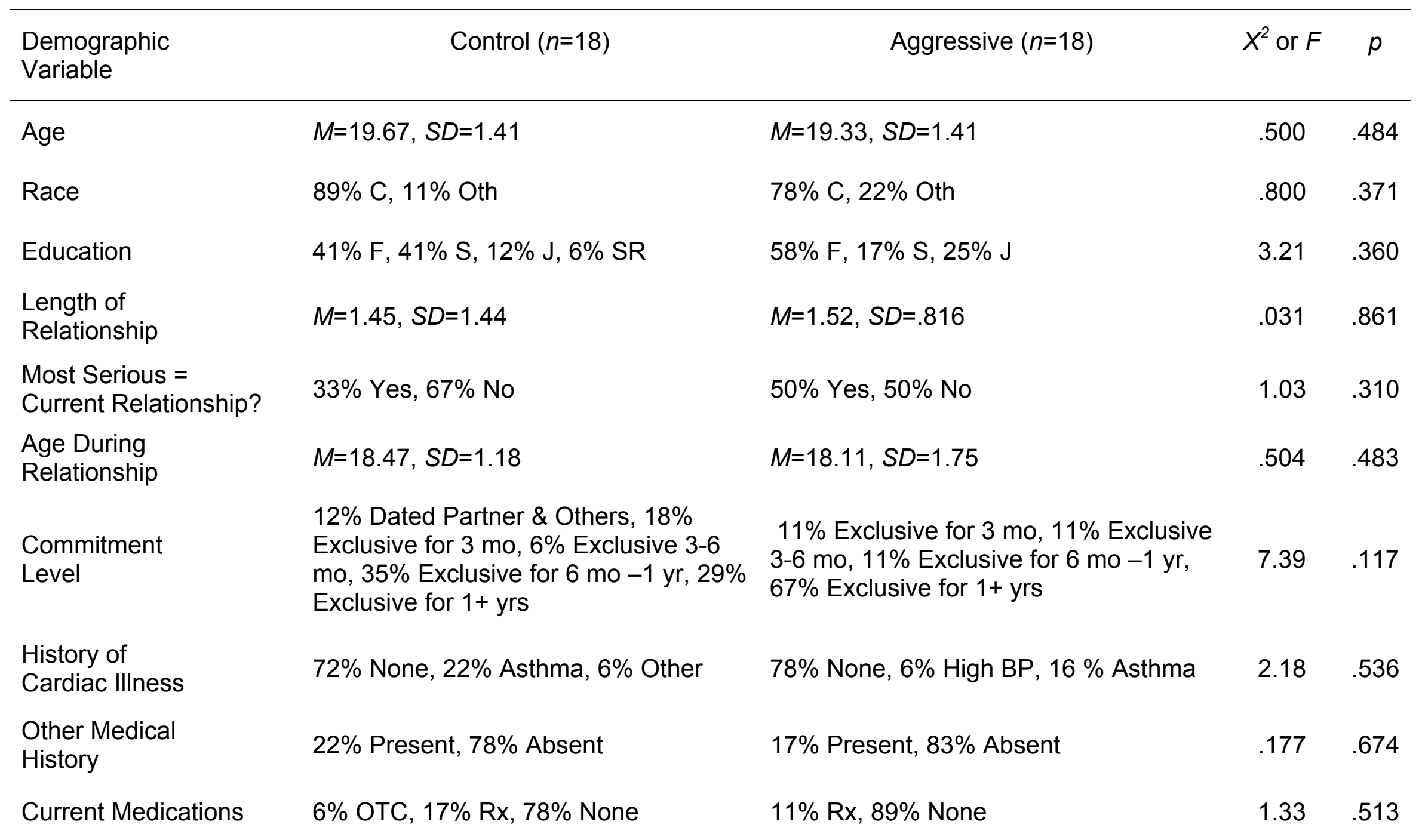




\begin{tabular}{|c|c|c|c|c|}
\hline Smoking Status & 78\% Nonsmoker, 22\% Smoker & $56 \%$ Nonsmoker, 44\% Smoker & 2.00 & .157 \\
\hline Parental Conflict & 22\% None, 72\% Verbal, 6\% Physical & $17 \%$ None, $83 \%$ Verbal & 1.29 & .526 \\
\hline $\begin{array}{l}\text { Severity of } \\
\text { Parental Conflict }\end{array}$ & $\begin{array}{l}94 \% \text { No physical injury or emotional } \\
\text { scar, } 6 \% \text { lasting damage }\end{array}$ & $\begin{array}{l}94 \% \text { No physical injury or emotional } \\
\text { scar, } 6 \% \text { lasting damage }\end{array}$ & .002 & .967 \\
\hline $\begin{array}{l}\text { Most Frequent Parental } \\
\text { Conflict }\end{array}$ & $\begin{array}{l}\text { 19\% Male Aggressor, } 6 \% \text { Female } \\
\text { Aggressor, } 75 \% \text { Both Aggressive }\end{array}$ & $\begin{array}{l}6 \% \text { Male Aggressor, } 6 \% \text { Female } \\
\text { Aggressor, } 88 \% \text { Both Aggressive }\end{array}$ & 1.30 & .521 \\
\hline $\begin{array}{l}\text { Personal History of } \\
\text { Fighting }\end{array}$ & $44 \%$ No, $56 \%$ Yes & $28 \%$ No, $72 \%$ Yes & 1.08 & .298 \\
\hline
\end{tabular}

Note: $\mathrm{C}=$ Caucasian, Oth $=$ Other. $\mathrm{F}=$ Freshman, $\mathrm{S}=$ Sophomore, $\mathrm{J}=$ Junior, $\mathrm{SR}=$ Senior. BP $=$ Blood Pressure. OTC $=$ Over-the-Counter, $\mathrm{Rx}=$ Prescription.

$\mathrm{X}^{2}$ values rather than $F$ values are presented for all demographic variables except age, length of most serious relationship, and age during most serious relationship, which were measured as continuous variables where 1 unit $=1$ year. 


\section{Testing for Order Effects.}

To ensure that order effects were absent, one-way ANOVAs were performed to compare participants' subjective reports of arousal (as measured by the STAXI state scales) to the scenario that was received first (i.e., "noise" or "mess"). Since counterbalancing procedures had been used, no differences were anticipated. Further tests for order effects included one-way ANOVAs to compare participants' objective reports of arousal (as determined by heart rate change scores) to their initial scenarios. Given that the scenarios were standardized to be parallel forms, no differences were expected. No differences emerged for either subjective or objective indices of arousal when compared to discussion task scene order. Table 3 outlines the results of these comparisons. An absence of significant differences here indicates that counterbalancing techniques were effective and that participants did not differentially respond to either scenario (i.e., no more arousal to "noise" scene than "mess" scene or vice versa). It also rules out the possibility that participants responded differently to the order of presentation of the two scenarios (i.e., there was no pattern of stronger reactions to the first or second scenes). Finally, participants were randomly assigned to complete the MMPI-2 either before or after the heart rate measurement condition. This was done to eliminate the possibility of MMPI-2 order effects. 
Table 3

Order Effects Analyses ${ }^{2}$ For Presentation of Discussion Task Scenarios: Subjective and Objective Reports of Arousal

\begin{tabular}{|c|c|c|c|c|c|c|c|}
\hline Measure & Noise & Scene & Mess & Scene & $n^{2}$ & $F(\mathrm{df})$ & $p$ \\
\hline & $M$ & $S D$ & $M$ & $S D$ & & & \\
\hline $\begin{array}{r}\text { STAXI State } 1 \\
\text { (Total) }\end{array}$ & 22.61 & 7.75 & 22.94 & 9.48 & .000 & $.013(34)$ & .909 \\
\hline $\begin{array}{r}\text { STAXI State } 1 \\
\text { Feelings }\end{array}$ & 9.11 & 3.60 & 8.67 & 3.78 & .004 & $.131(34)$ & .720 \\
\hline $\begin{array}{r}\text { STAXI State } 1 \\
\text { Verbal }\end{array}$ & 7.67 & 3.58 & 8.11 & 4.10 & .004 & $.120(34)$ & .731 \\
\hline $\begin{array}{r}\text { STAXI State } 1 \\
\text { Physical }\end{array}$ & 5.83 & 1.76 & 5.89 & 2.37 & .000 & $.006(34)$ & .937 \\
\hline $\begin{array}{r}\text { STAXI State } 2 \\
\text { (Total) }\end{array}$ & 26.39 & 8.27 & 24.22 & 9.72 & .015 & $.519(34)$ & .476 \\
\hline $\begin{array}{r}\text { STAXI State } 2 \\
\text { Feelings }\end{array}$ & 10.94 & 4.50 & 9.83 & 4.29 & .017 & $.575(34)$ & .454 \\
\hline $\begin{array}{r}\text { STAXI State } 2 \\
\text { Verbal }\end{array}$ & 9.44 & 3.99 & 8.44 & 4.00 & .016 & $.564(34)$ & .458 \\
\hline $\begin{array}{r}\text { STAXI State } 2 \\
\text { Physical }\end{array}$ & 6.00 & 1.68 & 6.11 & 2.63 & .001 & $.023(34)$ & .881 \\
\hline
\end{tabular}




\begin{tabular}{|c|c|c|c|c|c|c|c|}
\hline $\begin{array}{r}\text { Heart Rate } \\
\text { Change } 1\end{array}$ & 6.70 & 6.06 & 9.87 & 7.62 & .053 & $1.91(34)$ & .176 \\
\hline Heart Rate & & & & & & & \\
\hline Change 2 & 7.06 & 5.09 & 7.99 & 5.84 & .007 & $.254(34)$ & .617 \\
\hline
\end{tabular}

Note: STAXI = State Trait Anger Expression Inventory. Subjective reports of arousal are determined by scores on STAXI state subscales scores. State 1 = following initial discussion task and State 2 = following second discussion task. Heart Rate Change 1 = difference in mean beats per minute measure from baseline 1 to interaction 1. Heart Rate Change 2 = difference in mean beats per minute measure from baseline 2 to interaction 2 . 


\section{MMPI-2.}

Mean group T-scores and standard deviations for the ten basic clinical and three primary validity scales of the MMPI-2 are presented in Table 4. A series of one-way ANOVAs revealed no significant differences between group mean T-scores for these 13 scales. The analysis was first performed using all participants, despite the fact that some participants had invalid MMPI-2 profiles (based on their validity scale scores). To determine whether this was impacting the outcome of the omnibus test, subsequent ANOVAs were performed with invalid profiles eliminated. First, participants with $\mathrm{F}$ (Infrequency) scale T-scores higher than 65 were excluded. No differences emerged from the subsequent analysis. Secondly, any participant who scored higher than 65 on the $L$ (Lie) scale was eliminated and the ANOVA was repeated. Again, no differences were detected between the aggressive and non-aggressive groups. Finally, those with low (i.e., <45) K (Correction) scale scores were eliminated and the analysis was run a third time. As before, no differences were present. This indicates that, although many of the participants produced invalid MMPI-2 profiles, the occurrence of such a profile was distributed evenly across experimental groups. It was predicted that participants in the aggressive groups would have higher scores on scale $4(\mathrm{Pd})$ than those in the control group. Since this was not found, the hypothesis that aggressive males would exhibit more antisocial behavior than their non-aggressive peers was rejected. See Table 4. 
Table 4

Minnesota Multiphasic Personality Inventory, second edition T-scores, F Values, $\mathrm{n}^{2}$ Values, and Significance by

\section{Group}

\begin{tabular}{|c|c|c|c|c|c|c|c|}
\hline \multirow[t]{2}{*}{$\begin{array}{l}\text { MMPI-2 } \\
\text { Subscale }\end{array}$} & \multicolumn{2}{|c|}{$\begin{array}{l}\text { Control } \\
(n=18)\end{array}$} & \multicolumn{2}{|c|}{$\begin{array}{l}\text { Aggressive } \\
(n=18)\end{array}$} & \multirow[t]{2}{*}{$n^{2}$} & \multirow[t]{2}{*}{$F(\mathrm{df})$} & \multirow[t]{2}{*}{$p$} \\
\hline & $M$ & $S D$ & $M$ & $S D$ & & & \\
\hline L & 54.22 & 14.55 & 51.11 & 17.52 & .010 & $.336(34)$ & .556 \\
\hline $\mathrm{F}$ & 53.67 & 9.02 & 64.50 & 25.45 & .079 & $2.90(34)$ & .098 \\
\hline K & 45.78 & 9.39 & 44.17 & 9.85 & .007 & $.252(34)$ & .619 \\
\hline 1(Hypochondriasis) & 50.56 & 7.91 & 56.33 & 12.82 & .072 & $2.65(34)$ & .113 \\
\hline 2 (Depression) & 50.44 & 11.14 & 51.61 & 11.21 & .003 & $.098(34)$ & .756 \\
\hline 3 (Hysteria) & 49.50 & 8.69 & 53.33 & 12.88 & .031 & $1.10(34)$ & .302 \\
\hline 4 (Psychopathic Deviate) & 52.56 & 12.20 & 60.00 & 15.57 & .070 & $2.55(34)$ & .120 \\
\hline
\end{tabular}




\begin{tabular}{|c|c|c|c|c|c|c|c|}
\hline \multirow[t]{2}{*}{$\begin{array}{l}\text { MMPI-2 } \\
\text { Subscale }\end{array}$} & \multicolumn{2}{|c|}{$\begin{array}{l}\text { Control } \\
(n=18)\end{array}$} & \multicolumn{2}{|c|}{$\begin{array}{l}\text { Aggressive } \\
\qquad(n=18)\end{array}$} & \multirow[t]{2}{*}{$n^{2}$} & \multirow[t]{2}{*}{$F(\mathrm{df})$} & \multirow[t]{2}{*}{$p$} \\
\hline & $M$ & $S D$ & $M$ & $S D$ & & & \\
\hline 5(Masculinity-Femininity) & 47.11 & 7.92 & 50.17 & 8.18 & .037 & $1.30(34)$ & .263 \\
\hline 6 (Paranoia) & 55.44 & 16.75 & 62.72 & 16.84 & .047 & $1.69(34)$ & .202 \\
\hline 7 (Psychasthenia) & 58.83 & 11.93 & 62.17 & 14.73 & .016 & $.557(34)$ & .461 \\
\hline 8 (Schizophrenia) & 60.17 & 14.89 & 65.27 & 19.21 & .023 & $.796(34)$ & .379 \\
\hline 9 (Hypomania) & 69.33 & 10.95 & 66.44 & 13.17 & .015 & $.512(34)$ & .479 \\
\hline $\begin{array}{l}0 \text { (Social Introversion- } \\
\text { Extroversion }\end{array}$ & 46.78 & 6.92 & 50.33 & 13.56 & .028 & $.983(34)$ & .329 \\
\hline
\end{tabular}


$\underline{\text { STAXI. }}$

One-way ANOVAs were used to determine if there were any differences in participants' experiences of anger, dispositions to experience anger, or ways in which anger is generally expressed as measured by the STAXI-2. All primary STAXI-2 scales and subscales were included in the analysis. The trait scale consists of two subscales: temperament and reaction. Trait STAXI-2 scores assess an individual's general feelings or reactions, not necessarily those experienced at the time of completion of the form. The control scale of the STAXI-2 provides a description of how a person deals with his anger (e.g., whether angry feelings are suppressed or overtly expressed). This scale is comprised of the anger control in, anger control out, anger expression in, and anger expression out subscales. The STAXI-2 state scale provides an index of situational anger and was completed by participants following each of the discussion tasks. The feelings, verbal, and physical subscales comprise the state scale.

No differences were found between the control and aggressive participants on the STAXI-2 control or state scales. This suggests that aggressive and non-aggressive men did not differ in how they experienced or reported that they express their anger. In addition, a finding of no differences on the STAXI-2 state scale indicates that participants in the two experimental groups did not differ in subjective reports of the level of arousal that they felt following each discussion task. Differences for the accompanying STAXI-2 state or control subscales were also not detected. ANOVAs of the STAXI-2 trait scale, however, 
revealed that aggressive males were generally angrier than were non-aggressive men $\left[F(1,34)=10.04, p<.01, n^{2}=.228\right]$. Furthermore, aggressive males reported having angrier temperaments $\left[F(1,34)=6.62, p<.05, n^{2}=.163\right]$ and being more prone to angry reactions $\left[F(1,33)=6.52, p<.01, n^{2}=.165\right]$ than those in the control group. This was expected since the Conflict Tactics Scale items that were used to categorize participants commonly involve behaviors that may have anger as a primary antecedent. Therefore, the finding of trait anger differences among experimental groups serves as a manipulation check to verify that aggressive men were generally angrier than non-aggressive males. Table 5 summarizes STAXI-2 data for aggressive and non-aggressive participants. 
Table 5

State Trait Anger Expression Inventory, Revised Scores, $\mathrm{n}^{2}$ Values, F Values, and Significance by Group

\begin{tabular}{rccccccc}
\hline $\begin{array}{c}\text { STAXI-2 } \\
\text { Scale }\end{array}$ & \multicolumn{2}{c}{$\begin{array}{c}\text { Control } \\
(n=18)\end{array}$} & \multicolumn{2}{c}{$\begin{array}{c}\text { Aggressive } \\
(n=18)\end{array}$} & $n^{2}$ & $F(\mathrm{df})$ & $p$ \\
\hline Trait (Total) & 17.22 & 4.75 & 24.00 & 6.94 & .228 & $10.04(34)$ & .003 \\
Temperament & 6.22 & 2.41 & 8.72 & 3.34 & .163 & $6.62(34)$ & .015 \\
Reaction & 8.35 & 2.62 & 10.83 & 3.09 & .165 & $6.52(33)$ & .015 \\
Control (Total) & 33.28 & 13.92 & 41.12 & 13.42 & .080 & $2.87(33)$ & .100 \\
Ang Control In & 24.17 & 4.93 & 22.06 & 5.21 & .044 & $1.51(33)$ & .227 \\
Ang Control Out & 25.11 & 4.85 & 23.76 & 4.02 & .023 & $.794(33)$ & .379 \\
Anger Expr In & 17.61 & 4.37 & 19.47 & 6.12 & .032 & $1.08(33)$ & .306 \\
Anger Expr Out & 17.17 & 4.05 & 19.53 & 4.50 & .075 & $2.62(33)$ & .112 \\
State 1 (Total) & 22.22 & 9.08 & 23.33 & 8.18 & .004 & $.149(34)$ & .702 \\
Feelings 1 & 9.06 & 3.78 & 8.72 & 3.59 & .002 & $.074(34)$ & .788 \\
Verbal 1 & 7.22 & 3.59 & 8,56 & 3.99 & .032 & $1.11(34)$ & .299
\end{tabular}




\begin{tabular}{rccccccc}
\hline $\begin{array}{c}\text { STAXI-2 } \\
\text { Scale }\end{array}$ & \multicolumn{2}{c}{$\begin{array}{c}\text { Control } \\
(n=18)\end{array}$} & \multicolumn{2}{c}{$\begin{array}{c}\text { Aggressive } \\
(n=18)\end{array}$} & $n^{2}$ & $F(\mathrm{df})$ & $p$ \\
\hline Physical 1 & 5.83 & 2.36 & 5.89 & 1.78 & .000 & $.006(34)$ & .937 \\
State 2 (Total) & 23.94 & 9.53 & 26.67 & 8.40 & .024 & $.827(34)$ & .370 \\
Feelings 2 & 9.78 & 4.29 & 11.00 & 4.49 & .020 & $.698(34)$ & .409 \\
Verbal 2 & 8.22 & 3.90 & 9.67 & 4.01 & .034 & $1.20(34)$ & .281 \\
Physical 2 & 6.11 & 2.61 & 6.00 & 1.72 & .001 & $.023(34)$ & .881 \\
\hline
\end{tabular}

Note: STAXI-2 = State Trait Anger Expression Inventory, Revised. Ang = Anger. Expr $=$ Expression

State 1 = STAXI-2 state scores following initial discussion task.

State 2 = STAXI-2 state scores following second discussion task. 
Heart Rate Comparisons (Baselines Included).

To determine whether there were group differences in baseline, interaction, or change (from baseline to interaction) heart rate means, individual data files were compiled and incorporated into a central database. Change scores were used as the index of heart rate reactivity. Contrary to what was predicted, no subgroup of heart rate decelerators was detected in the aggressive group. In fact, only four participants exhibited heart rate decelerations at all: three (two control and one aggressive) during change 1, and one (control) during change 2. Individual heart rate data files were comprised of all heart rate data entries (taken at five-second intervals and measured in beats per minute) for a participant during initial baseline, first interaction, return to baseline, and final interaction conditions. The means of each of these four conditions and their accompanying reactivity scores were calculated and transferred into the central file to determine the group heart rate means (aggressive and non-aggressive) for all conditions. These values were then utilized for all subsequent analyses.

When one-way ANOVAs were performed, no omnibus differences emerged. Therefore, the groups did not differ in regard to resting (baseline) heart rate. Furthermore, the participants in the aggressive and non-aggressive groups responded similarly to each of the discussion task (interaction) conditions. See Table 6. 
Table 6

Heart Rate Means, Standard Deviations, $\mathrm{n}^{2}$ Values, F Values, and Significance by Group

\begin{tabular}{lccccccc}
\hline Heart Rate & \multicolumn{2}{c}{$\begin{array}{c}\text { Control } \\
(n=18)\end{array}$} & \multicolumn{2}{c}{$\begin{array}{c}\text { Aggressive } \\
(n=18)\end{array}$} & $n^{2}$ & $F(\mathrm{df})$ & $p$ \\
\hline & $M$ bpm & $S D$ & $M$ bpm & $S D$ & & & \\
Baseline 1 & 81.10 & 11.88 & 75.68 & 14.27 & .143 & $1.53(34)$ & .224 \\
Interaction 1 & 89.89 & 13.17 & 83.47 & 13.06 & .060 & $2.16(34)$ & .151 \\
Change 1 & 8.78 & 6.60 & 7.78 & 7.48 & .005 & $.182(34)$ & .672 \\
Baseline 2 & 78.10 & 11.17 & 73.90 & 12.33 & .033 & $1.15(34)$ & .292 \\
Interaction 2 & 85.90 & 11.27 & 81.16 & 11.59 & .043 & $1.54(34)$ & .223 \\
Change 2 & 7.79 & 5.60 & 7.26 & 5.39 & .002 & $.082(34)$ & .776 \\
\hline
\end{tabular}

Note: Baseline $1=$ the last three minutes of the baseline period that the participant was alone in the room.

Interaction $1=$ the entire three minutes of the initial discussion task.

Change 1 = the difference between the means of Baseline 1 and Interaction 1.

Baseline 2 = the last three minutes of the return to baseline period that the participant was alone in the room.

Interaction 2 = the entire three minutes of the second discussion task.

Change $1=$ the difference between the means of Baseline 2 and Interaction 2. 
Heart Rate Comparisons (Baselines Covaried).

Analyses of covariance (ANCOVAs) were performed to estimate their responses without the impact of the baseline. By covarying the baseline from each interaction and analyzing the change score, a more pure measure of responding could be attained for each group. The ANCOVAs, however, also failed to yield significant differences between the aggressive and non-aggressive males' heart rate reactivity to either of the discussion tasks. This further confirmed that the groups did not differ in their physiological (objective) response to the discussion tasks. Table 7 outlines ANCOVA results for aggressive and non-aggressive males' heart rate reactivities. 
Table 7

Heart Rate Changes with Baselines as Covariates: Change Scores, $n^{2}$ Values, F Values, and Significance.

\begin{tabular}{|c|c|c|c|c|c|c|c|}
\hline \multirow{2}{*}{$\begin{array}{l}\text { Heart } \\
\text { Rate } \\
\text { Changes }\end{array}$} & \multicolumn{2}{|c|}{$\begin{array}{l}\text { Control } \\
(n=18)\end{array}$} & \multicolumn{2}{|c|}{$\begin{array}{l}\text { Aggressive } \\
\quad(n=18)\end{array}$} & \multirow[t]{2}{*}{$n^{2}$} & \multirow[t]{2}{*}{$F(\mathrm{df})$} & \multirow[t]{2}{*}{$p$} \\
\hline & $\begin{array}{c}M \\
\text { bpm }\end{array}$ & $S D$ & $\begin{array}{c}M \\
\mathrm{bpm}\end{array}$ & $S D$ & & & \\
\hline Change 1 & 8.79 & 6.61 & 7.78 & 7.48 & .078 & $1.40(33)$ & .261 \\
\hline Change 2 & 7.79 & 5.60 & 7.26 & 5.39 & .089 & $1.60(33)$ & .216 \\
\hline
\end{tabular}

Note: Change 1 = the difference between the means of Baseline 1 and Interaction 1.

Change 2 = the difference between the means of Baseline 2 and Interaction 2. 


\section{Heart Rate Comparisons (Extreme Scores).}

Median splits across groups were performed for each of the heart rate reactivity indices (change scores). For change 1 (baseline 1 to interaction 1) the mean reactivities were +8.79 beats per minute $(\mathrm{bpm})$ and $+7.78 \mathrm{bpm}$ for the control and aggressive groups, respectively. For change 2 reactivities were +7.79 bpm (control) and +7.26 bpm (aggressive). The split values were then recoded and Pearson Chi Square analyses were performed to compare the highest and lowest responders in each group. No differences were detected, suggesting that even the highest and lowest responders in each group did not have different heart rate reactivities. See Table 8 . 
Table 8

Pearson Chi Square Analyses of Median Split Heart Rate Changes

\begin{tabular}{|c|c|c|c|c|c|c|c|}
\hline \multirow[t]{2}{*}{$\begin{array}{l}\text { Median Split of } \\
\text { Heart Rate Change }\end{array}$} & \multirow[t]{2}{*}{ Median } & \multicolumn{2}{|c|}{$\begin{array}{l}\text { Control } \\
(n=18)\end{array}$} & \multicolumn{2}{|c|}{$\begin{array}{l}\text { Aggressive } \\
\qquad(n=18)\end{array}$} & \multirow{2}{*}{$\begin{array}{c}\text { Pearson } \\
\text { Chi- } \\
\text { Square(df) }\end{array}$} & \multirow[t]{2}{*}{$p$} \\
\hline & & $\begin{array}{l}\text { Below } \\
\text { Median }\end{array}$ & $\begin{array}{l}\text { Above } \\
\text { Median }\end{array}$ & $\begin{array}{l}\text { Below } \\
\text { Median }\end{array}$ & $\begin{array}{l}\text { Above } \\
\text { Median }\end{array}$ & & \\
\hline $\begin{array}{l}\text { Change } 1 \text { = Baseline } 1 \text { to } \\
\text { Interaction } 1\end{array}$ & 8.79 & $38.9 \%$ & $61.1 \%$ & $61.1 \%$ & $38.9 \%$ & $1.78(1)$ & .182 \\
\hline $\begin{array}{l}\text { Change } 2=\text { Baseline } 2 \text { to } \\
\text { Interaction } 2\end{array}$ & 5.87 & $44.4 \%$ & $55.6 \%$ & $55.6 \%$ & $44.4 \%$ & $.444(1)$ & .505 \\
\hline
\end{tabular}

Note: Median splits were calculated across groups. 


\section{Discussion}

This study was an evaluation of the generalizability of Gottman et al.'s (1995) physiologically-based typology of male batterers. Unfortunately, the identification of a subgroup of heart rate decelerators among aggressive males was not replicated. Furthermore, no significant differences were found between aggressive and non-aggressive males in terms of: (1) reported history of witnessing inter-parental aggression, (2) antisocial personality characteristics, (3) expression and control of angry impulses, or (4) physiologic response to analog conflict situations. As expected, aggressive men reported having angrier temperaments and being more prone to angry reactions than did non-aggressive men. A discussion of significant results of the study will be presented, followed by potential implications of non-significant findings. Limitations of the study and suggestions for future research will also be provided.

$\underline{\text { Significant Results }}$

\section{State Trait Anger Expression Inventory, Revised: Trait Scale and}

Subscales. Men in the aggressive group scored higher than non-aggressive men on the STAXI-2 trait total scale and the trait temperament and reaction subscales. Higher scores on the trait total score indicate that the aggressive men were generally more prone to anger than the non-aggressive men. Elevated scores on temperament and reaction subscales clarified the total score elevation by showing that these individuals frequently experienced anger, both with and without direct provocation (Spielberger, 1998). This finding validated the 
categorization of participants as aggressive or non-aggressive since it is logical that anger may be a common antecedent to aggressive behavior.

Non-significant Results

Demographic Variables. There were no differences between the aggressive and non-aggressive groups on any of the demographic or historical variables. Although differences in age, ethnicity, and related demographic variables were not expected, it was hypothesized that aggressive men would report witnessing greater inter-parental aggression than non-aggressive males. At least a portion of the aggressive men were also expected to report being involved in more fights than the men in the non-aggressive group. The lack of differences on these two variables suggests that the aggressive group was no more violent outside of the relationship context than the non-aggressive group. Also, exposure to aggression modeled by parents was similar for aggressive and non-aggressive males. The participants in Gottman et al.'s (1995) clinical sample of male batterers included men who had witnessed high levels of inter-parental aggression and engaged in violent behavior beyond the constraints of intimate partnerships. Since no such men were identified in the current study, perhaps the men in the aggressive group in this study were: (1) not as violent as those in the Gottman et al. sample, and (2) less likely to have engaged in aggressive behavior as a result of modeling during their childhoods.

Minnesota Multiphasic Personality Inventory, Revised (MMPI-2). No differences were found between aggressive and non-aggressive groups on any of the three standard validity or ten basic clinical scales of the MMPI-2. There 
were, however, several participants with invalid profiles. These participants were distributed relatively evenly across the two groups, so their inclusion did not affect the results. The fact that the males in the aggressive group were no more likely to endorse items associated with antisocial personality characteristics than the non-aggressive males is inconsistent with what would be predicted by Gottman et al.'s (1995) Type 1/Type 2 typology. That typology would predict that a subgroup of the aggressive males would report more antisocial tendencies indicating that they engaged in generalized (not just relational) aggression. This suggests that the aggressive men in this study were a relatively homogeneous group of mildly aggressive men rather than a heterogeneous sample of severe batterers similar to those used in the original Gottman et al. investigation.

\section{State Trait Anger Expression Inventory: Anger Control and Expression}

Scale and Subscales. Aggressive and non-aggressive males were not different in reporting how

they controlled and/or expressed their anger. This was not expected because it was hypothesized that the aggressive men were engaging in more violent behavior because they lacked the control that would prevent them from overt anger expression. If the aggressive men were indeed not expressing their anger differently (as a result of failing to control it), then it is unclear why they would report engaging in aggressive behavior on the Conflict Tactics Scale (used for classification). This illustrates how relying on self-report data can be problematic.

State Trait Anger Expression Inventory: State Scale and Subscales. Aggressive and non-aggressive participants did not differ in terms of subjective 
report of anger in response to discussion tasks. Instead, they reported similar levels of anger following both discussion tasks, regardless of the order of presentation. First, this serves as a manipulation check to indicate that the discussion tasks were parallel in nature. Secondly though, is suggests that the aggressive males were no more aroused than the non-aggressive males during what was intended to be a provocative, stress-inducing situation. The most likely explanation (particularly given that both groups displayed little physiologic reactivity) is that the discussion tasks were simply not the salient, confrontational stimuli they were expected to be. This explanation stems from the findings of other studies in which aggressive men report higher levels of internal arousal to conflict discussions with their wives than do non-aggressive men (e.g., Margolin, John, \& Gleberman, 1988).

Heart Rate Baselines and Reactivities. No differences were found between aggressive and non-aggressive groups' baseline heart rates or heart rate reactivities during discussion tasks. It was hypothesized that all participants would have similar resting heart rates or that the baseline heart rates of men in the aggressive group would be lower than those of the non-aggressive group. Given that baseline heart rate differences were absent, the two groups had generally similar physiologic functioning. When examining the participants within each group, however, large variations in baseline heart rates were found. Since this was coupled with a relatively small sample size ( $n=18$ for each group) this suggests that the aggressive and non-aggressive men had such wide ranges of resting heart rates that the group mean comparisons were not useful due to lack 
of statistical power. Lack of differences in reactivity indicates that, in contrast to what was predicted, the aggressive men were no more aroused by the discussion situation than were those in the control group. As with subjective reports of arousal (as measured by the STAXI-2 state scales), the similarity in objective (heart rate) measurement of arousal to the discussion tasks suggests that the discussion tasks may not have been as provocative as they were intended to be (i.e., none of the participants were highly aroused by the situations). This is supported by the fact that Larkin et al. (1998) found mean heart rate reactivity increases of 12.4 and 12.9 beats per minute using the noise and mess scenes, respectively, but the mean reactivity increases in this study were only 6.9 (noise) and 5.6 (mess) beats per minute. This is also inconsistent with the Gottman et al. (1995) who found reactivities ranging from +23.05 to 20.85 beats per minute. Mean heart rate reactivities were $-1.94(S D=1.41)$ and +5.09 $(S D=3.44)$ for Type1 and Type 2 males, respectively in that study.

Heart Rate Reactivities with Baselines Covaried. No reactivity differences were found when baselines were covaried out of the heart rate reactivity measurements. This is further evidence that the lack of differential responding between the two groups was due to similar reactivities and not attributable to baseline differences.

Heart Rate Reactivities: Extreme Scores. Pearson Chi Square analyses of the participants with the highest and lowest heart rate reactivities (as determined by a median split procedure) did not reveal any reactivity differences between aggressive (42\% high, 58\% low) and non-aggressive (58\% high, $42 \%$ low) 
males. This indicates that participants' heart rate reactivities were similar, even when looking at the extreme cases.

Limitations. The lack of differences across measures (with the exception of the STAXI-2 trait scales) suggests that there may have been problems with the procedures within the study. First, the males in the aggressive group would not likely be considered a clinical sample due to their low level of perpetrating violent acts. The aggressive men used in this study may have been so different from Gottman et al.'s (1995) clinical sample of 60 severe batterers that an assessment of the generalizability of Gottman et al.'s findings is not possible. The use of this relatively non-violent "aggressive" sample was necessitated by the fact that there was so much difficulty in identifying violent aggressive men in a university setting. Although approximately 750 males were screened, only 40 reported physical violence in their dating relationships and only five of these actually participated in the laboratory phase. This is significantly lower than what would be expected (e.g., if 10 to $20 \%$ of overall sample reported severe violence, then 75 to 150 violent men should have been identified).

It is likely that this occurred because: (1) males were asked to self-report relational aggression, and (2) they were then asked to have repeated contact with the examiner (i.e., to participate in the laboratory phase). Given that it is typically socially unacceptable to report behavior such as that described in the face-valid CTS-2, the males who were most aggressive likely minimized their violent behavior or refused to participate in the screening phase altogether. 
Adding a social desirability scale to the screening packet may have provided direct evidence of this.

It appears as if the aggressive and non-aggressive males in this study may not have been engaging in dramatically different behaviors in their dating relationships. This is not to say, necessarily, that aggressive and non-aggressive males do not have different behavioral repertoires. It is logical that men who are highly aggressive in their intimate relationships exhibit much different behavior patterns that those in non-aggressive relationships. The fact that this was not evident in the current sample, however, is likely because the men who were categorized as "aggressive" were actually near the lowest end of a continuum of increasingly more violent dating abuse perpetrators. Instead of engaging in acts like beating up, kicking, or punching their partner, the men in this aggressive sample described repetitively cursing at, making fun of, grabbing, or shoving their partners. These behaviors are clearly different in terms of their impact (i.e., acute, physical injury with associated psychological effects versus primarily psychological, but not physical impact, respectively). Although the current findings would suggest that Gottman et al's (1995) Type1/Type2 typology was not replicated in a sample of dating males, extreme caution must be used in interpretation because of the dramatic sample differences. Perhaps using unmarried males who had been identified as violent in their intimate relationship (e.g., from a court-ordered treatment program) would increase the likelihood of obtaining an aggressive sample more similar to that in the Gottman et al. study and eliminate the obstacle of teasing out social desirability effects. 
Secondly, the analog conflict situation may not have been an adequate model for intimate confrontation. Contrary to Larkin et al. (1998) and others, experimenter observations of the participants in this study revealed that most participants were reluctant to engage in conflict discussion with a stranger (the confederate female). The interaction with a stranger may have been too different from interacting with a romantic partner to consider these situations parallel. It appears that the experimental manipulation of the "noise" and "mess" discussion tasks was simply not as provocative or arousing to the aggressive participants as was anticipated. It was predicted that the aggressive males would have stronger reactions to the confrontational discussions than the non-aggressive males. This was simply not the case since differences were not found in heart rate reactivities between the two groups and because the aggressive males did not report feeling angrier (according to the STAXI-2 state scales) than the non-aggressive men following the discussions.

Also, it is possible that social desirability affected the aggressive participants in the laboratory as well as in the screening phase. It may be that aggressive males did not report higher levels of anger (as measured by STAXI-2 state scales) than non-aggressive males as they were expected to because they were reluctant to endorse items that seemed socially undesirable (e.g., "I feel like banging on the table", "I feel like shouting out loud"). Although it would be difficult for participants to control their physiologic responding, it may be that the men in the aggressive group failed to accurately report their feelings of anger due to selfimposed pressure to provide socially desirable answers. Again, including a 
measure of social desirability may have identified such participants and allowed the examiners to control for this factor during statistical analyses.

Finally, the small sample size limited statistical inference due to a lack of power and made generalization difficult because the sample was probably not inclusive enough to determine why differences were not found.

\section{Suggestions for Future Research}

Given the limitations of this study, it remains important for researchers to replicate or attempt to generalize Gottman et al.'s (1995) physiologically-based batterer typology. Since this study had limitations that prevented a true generalizability assessment, little data exists to either support or refute Gottman et al.'s Type1/Type 2 batterer categorization. As with any novel typology, it is crucial that the results of the Gottman et al. study be replicated before they are used as assessment or intervention guidelines.

Future studies may include direct replication of the Gottman et al. (1995) methodology with a clearly-identified clinical sample of male batterers. They may also further attempt to generalize the Gottman et al. results by utilizing a threegroup design of violent, psychologically aggressive (but nonviolent), and nonaggressive males (as was the original intention of these authors). Comparing batterers using different levels of violence as a categorization criteria would also be helpful in determining the point at which severe batterers (who use extremely violent tactics) and batters who exhibit only relatively minor physical aggression should be considered different in terms of intervention and treatment needs and strategies. 
Finally, using the female partner instead of a female confederate may increase the likelihood that men would respond in a manner consistent with what they employ in their actual relationship conflicts. Similar to Gottman et al. (1995) and Berns et al. (1999), asking these couples to identify recent conflicts and using them as interaction stimuli in place of the "noise" and "mess" scenes may also be more realistic and yield data more consistent with that which would be found in the naturalistic setting.

Identifying an empirically-validated typology of male batterers and the complex interaction of variables that characterize them could assist in assessment and intervention strategies. More importantly, identifying a typology for dating aggressive men may serve as a tool in preventing violence in intimate relationships altogether. 


\section{References}

Arias, I., \& Johnson, P. (1989). Evaluations of physical aggression among intimate dyads. Journal of Interpersonal Violence, 4, 298-307.

Arias, I., Samios, L., \& O'Leary, K. (1987). Prevalence and correlates of physical aggression during courtship. Journal of Interpersonal Violence, 2, 82-90.

Bandura, A. (1965). Influence of models' reinforcement contingencies in the acquisition of imitative responses. Journal of Personality and Social Psychology, 1, 589-595.

Bandura, A. (1973). Aggression: A Social Learning Analysis. Englewood Cliffs, NJ: Prentice-Hall.

Bernard, M. L., \& Bernard, J. L. (1983). Violent intimacy: The family as a model for love relationships. Family Relations, 32, 283-286.

Berns, S. B., Jacobson, N. S., \& Gottman, J. M. (1999). Demand/withdraw interaction patterns between different types of batterers and their spouses. Journal of Marital and Family Therapy, 25, 337-348.

Brown, P. C., \& Smith, T. W. (1992). Social influence, marriage, and the heart: Cardiovascular consequences of interpersonal conflict in husbands and wives. Health Psychology, 11, 88-96.

Browne, A. (1993). Violence against women by male partners: Prevalence, outcomes, and policy implications. American Psychologist, 48(10), 10771087.Bureau of Justice Statistics. (2000). Special Report: Intimate Partner Violence, Retrieved 8/30/01 from The United States Department of Justice Homepage. 
Burns, J. W., \& Katkin, E. S. (1993). Psychological, situational, and gender predictors of cardiovascular reactivity to stress: A multivariate approach. Journal of Behavioral Medicine, 16, 445-465.

Butcher, J. N., Dahlstrom, W. G., Graham, J. R., Tellegen, A., \& Kaemmer, B. (1989). MMPI-2: Manual for administration and scoring. Minneapolis, MN: University of Minnesota Press.

Casanova, G. M., Domanic, J., McCanne, T. R., \& Milner, J. S. (1992). Physiological responses to non-child-related stressors in mothers at risk for child abuse. Child Abuse and Neglect, 16, 31-44.

Dutton, D. G. (1998). The Abusive Personality. New York: Guilford Press.

Forgays, D. G., Forgays, D. K., \& Spielberger, C. D. (1997). Factor structure of the state-trait anger expression inventory. Journal of Personality Assessment, 69, 497-507.

Friedman, M., \& Rosenman, R. H. (1974). Type A Behavior and Your Heart. Greenwich, CT: Corbett.

Goodie, J., Schauss, S. L., Larkin, K. T., \& Aragona, B. (1997). Validation of the Polar heart rate monitor for measuring heart rate responses to mental stress. Psychophysiology, 34, S38. Paper presented at the $37^{\text {th }}$ Annual Meeting of the Society for Psychophysiological Research, Cape Cod, MA.

Gottman, J. M., Jacobson, N. S., Rushe, R. H., Shortt, J. W., Babcock, J., La Taillade, J. J., \& Waltz, J. (1995). The relationship between heart rate reactivity, emotionally aggressive behavior, and general violence in batterers. Journal of Family Psychology, 9, 227-248. 
Greene, R. L. (2000). The MMPI-2: An Interpretive Manual. Second Ed. Needham Heights, MA: Allyn \& Bacon.

Hamberger, K., \& Hastings, J. (1986). Personality correlates of men who abuse their partners: A cross-validational study. Journal of Family Violence, 1, 323-341.

Holtzworth-Munroe, A., \& Anglin, K. (1991). The competency of responses given by martially violent versus nonviolent men to problematic marital situations. Violence \& Victims, 6, 257-269.

Holtzworth-Munroe A., \& Stuart, G. (1994). Typologies of male batterers: Three subtypes and the differences among them. Psychological Bulletin, 116, 476-497.

Jacobson, N. S., Gottman, J. M., Waltz, J., Rushe, R., Babcock, J., \& HoltzworthMunroe, A. (1994). Journal of Consulting and Clinical Psychology, 62, 982-988.

Kasian, M., \& Painter, S. (1992). Frequency and severity of psychological abuse in a dating population. Journal of Interpersonal Violence, 7, 350-364.

Krantz, D. S., Manuck, S. B., \& Wing, R. R. (1986). Psychological stressors and task variables as elicitors of reactivity. In K. Matthews, S. Weiss, T. Detre, T. Dembrowski, B. Falkner, S. Manuck, \& R. Williams, (Eds.). Handbook of Stress, Reactivity, and Cardiovascular Disease. New York: John Wiley \& Sons.

Larkin, K. T., Semenchuk, E. M., Frazier, N. L., Suchday, S., \& Taylor, R. L. (1998). Cardiovascular and behavioral response to social confrontation: 
Measuring real-life stressors in the laboratory. Annals of Behavioral Medicine, 20, 294-301.

Larsen, P., Schneiderman, N., \& Pasin, R. (1986). Physiological bases of cardiovascular psychophysiology. In M. Coles, E. Donchin, \& S. Porges (Eds.). Psychophysiology: Systems, Processes, and Applications (pp. 122-165). New York: Guilford Press.

LeJeune, C., \& Follette, V. (1994). Taking responsibility: Sex differences in reporting dating violence. Journal of Interpersonal Violence, 9, 133-140.

Lewis, S. F., \& Fremouw, W. (2001). Dating violence: A critical review of the literature. Clinical Psychology Review, 21, 105-127.

Magdol, L., Moffitt, T. E., Caspi, A., Newman, D. L., Fagan, J., \& Silva, P. A. (1997). Gender differences in partner violence in a birth cohort of 21-yearolds:Bridging the gap between clinical and epidemiological approaches. Journal of Consulting and Clinical Psychology, 65, 68-78.

Makepeace, J. M. (1981). Courtship violence among college students, Family Relations, 30, 97-102.

Makepeace, J. M., (1986). Gender differences in courtship violence victimization. Family Relations, 35, 383-388.

Malloy, K. A., McCloskey, K. A., \& Monford, T. M. (1999). A group treatment program for male batterers. In L. VandeCreek and T. L. Jackson (Eds.), Innovations in Clinical Practice: A Source Book (pp. 377-395). Sarasota, FL: Professional Resource Press.

Manuck, S. Kamarck, T., Kasprowicz, A., \& Waldstein, S. (1995). Stability and 
patterning of behaviorally evoked cardiovascular reactivity. In J.

Blascovich \& E. S. Katkin (Eds.). Cardiovascular Reactivity to

Psychological Stress and Disease. Washington, D. C.:

American Psychological Association.

Margolin, G., Gordis, E. B., Oliver, P. H., \& Raine, A. (1995). A physiologically based typology of batterers-Promising, but preliminary: Comment on Gottman et al. (1995). Journal of Family Psychology, 9, 253-263.

Margolin, G., John, R. S., \& Gleberman, L. (1988). Affective responses to conflictual discussions in violent and nonviolent couples. Journal of Consulting and Clinical Psychology, 56, 24-33.

Mezzacappa, E., Tremblay, R. E., Kindlon. D., Saul, J. P., Arseneault, L., Seguin, J., Pihl, R. O., \& Earls, F. (1997). Anxiety, antisocial behavior, and heart rate regulation in adolescent males. Journal of Child Psychol. Psychiat., 38, 457-469.

Murphy, C., \& Hoover, S. (1999). Measuring emotional abuse in dating relationships as a multifactorial construct. Violence and Victims, 14, 39-53.

O'Hearn, R., \& Davis, K. (1997). Women's experience of giving and receiving emotional abuse: An attachment perspective. Journal of Interpersonal Violence, 12, 375-391.

Ornduff, S. R., Kelsey, R. M., O'Leary, K. D. (1995). What do we know about typologies of batterers? Comment on Gottman et al. (1995). Journal of Family Psychology, 9, 249-252.

Riggs, D., O’Leary, K., \& Breslin, F. (1990). Multiple predictors of physical 
aggression in dating couples. Journal of Interpersonal Violence, 5, 61-73.

Sackett, L. A., \& Saunders, D. G. (1999). The impact of different forms of psychological abuse on battered women. Violence and Victims, 14, 105117.

Saunders, D. G. (1992). A Typology of men who batter: Three types derived from cluster analysis. American Journal of Orthopsychiatry, 62, 264-275.

Smith, T. W., \& Brown, P. C. (1991). Cynical hostility, attempts to exert social control, and cardiovascular reactivity in married couples. Journal of Behavioral Medicine, 14, 581-592.

Smith, T., Gallo, L., Goble, L., Ngu, L., \& Stark, K. (1998). Agency, communication, and cardiovascular reactivity during marital interaction. Health Psychology, 17, 537-545.

Spielberger, C. D. (1998). Manual for the State-Trait Anger Expression Inventory. Odessa, FL: Psychological Assessment Resources.

Spielberger, C. D., Ritterband, L. M., Sydeman, S. J., Reheiser, E. C., \& Unger, K. K. (1995). Assessment of emotional states and personality traits: Measuring psychological vital signs. In J. N. Butcher (Ed.). Clinical Personality Assessment: Practical Approaches (pp.42-58). New York: Oxford University Press.

Spielberger, C. D., \& Sydeman, S. J. (1994). State Trait Anxiety Inventory and State-Trait Anger Expression Inventory. In M. E. Maruish (Ed.), The Use of Psychological Tests for Treatment Planning and Outcome Assessment (pp. 292-321). Hillsdale, NJ: LEA. 
Straus, M. (1979). Measuring intrafamily conflict and violence: The Conflict Tactics (CT) scale. Journal of Marriage and the Family, 41, 75-86.

Straus, M., \& Gelles, R. (1986). Societal change and change in family violence from 1975 to 1985 as revealed by two national surveys. Journal of Marriage and the Family, 48, 465-479.

Straus, M. A., Hamby, S. L., Boney-McCoy, S., \& Sugarman, D. B. (1996). The revised conflict tactics scales (CTS2): Development and preliminary psychometric data. Journal of Family Issues, 17, 283-316.

Straus, M. A., Gelles, R. J., \& Steinmetz, S. K. (1980). Behind Closed Doors: Violence in the American Family. New York: Doubleday.

Sugarman, D. \& Hotaling, G. (1989). Dating Violence: Prevalence, context, and risk markers. In M. Pirog-Good and J. Stets (Eds.). Violence and Dating Relationships. New York: Praeger.

Suls, J., \& Wan, C. K. (1993). The relationship between trait hostility and cardiovascular reactivity. A quantitative review and analysis. Psychophysiology, 30, 615-626.

Tolman, R. M., (1999). The validation of the psychological maltreatment of women inventory. Violence and Victims, 14, 25-37.

Tweed, R. G., \& Dutton, D. G. (1998). A comparison of impulsive and instrumental subgroups of batterers. Violence \& Victims, 13, 217-230.

Walker, L. (1984). The Battered Woman Syndrome. New York: Springer. White, J., \& Koss, M. (1991). Courtship violence: Incidence in a national sample of higher education students. Violence and Victims, 6, 247-256. 
Appendix A

Classification Criteria for Experimental Groups

Relevant CTS-2 Items:

\section{Minor Psychological Aggression Items}

- Insulted or swore at my partner

- Shouted or yelled at my partner

- Stomped out of the room or house or yard during a disagreement

- Said something to spite my partner

\section{Severe Psychological Aggression Items}

- Called my partner fat or ugly

- Destroyed something belonging to my partner

- Accused my partner of being a lousy lover

- Threatened to hit or throw something at my partner

\section{Minor Physical Assault Items}

- Threw something at my partner that could hurt

- Twisted my partner's arm or hair

- Pushed or shoved my partner

- Grabbed my partner

- Slapped my partner

\section{Severe Physical Assault Items}

- Used a knife or gun on my partner

- Punched or hit my partner with something that could hurt

- Choked my partner

- Slammed my partner against a wall

- Beat up my partner 
- Burned or scalded my partner on purpose

- Kicked my partner

Classification Criteria:

To be classified as a "control" participant the male must report meeting the following criteria during the most serious relationship (up to 1 year):

- No minor or severe physical assault

- Only low levels* of minor psychological aggression

- No severe psychological aggression

To be classified as an "aggressive" participant the male must report meeting the following criteria during the most serious relationship (up to 1 year):

- High levels ${ }^{\star *}$ of minor psychological aggression

- Any severe psychological aggression

and/or

- Any minor or severe physical assault

* Low Levels $=$ Less than 5 times for each item

${ }^{* *}$ High Levels $=6$ or more times for each item 


\author{
Appendix B \\ Conflict Tactics Scale, Revised
}

\title{
CTS2
}

\section{$\underline{\text { Relationship Behaviors }}$}

No matter how well a couple gets along, there are times when they disagree, get annoyed with the other person, want different things from each other, or just have spats or fights because they are in a bad mood, are tired, or for some other reason. Couples also have many different ways of trying to settle their differences. This is a list of things that might happen if you have differences. Please circle how many times you did these things during the Year of your MOST SERIOUS relationship and how many times your partner did them within that Year. If you or your partner did not do one of these things within that year, but it had happened before that, circle "7."

\section{$0=$ This has never happened \\ $1=$ Once within that year \\ $2=$ Twice within that year \\ $3=3-5$ times within that year \\ $4=6-7$ times within that year \\ $5=11-20$ times within that year \\ $6=$ More than 20 times within that year \\ 7 = Did not happen within that year, but it has happened before}

1. I made my partner have sex without a condom.

2. My partner did this to me.

3. I pushed or shoved my partner.

4. My partner did this to me.

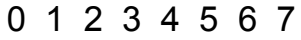

$\begin{array}{llllllll}0 & 1 & 2 & 3 & 4 & 5 & 6 & 7\end{array}$

$0 \begin{array}{lllllll}0 & 1 & 2 & 3 & 5 & 6 & 7\end{array}$

$0 \begin{array}{lllllll}0 & 1 & 3 & 4 & 5 & 6 & 7\end{array}$

5. I used force (like hitting, holding down, or using a weapon) to make my partner have oral or anal sex.

6. My partner did this to me.

7. I used a knife or gun on my partner.

8. My partner did this to me.

9. I passed out from being hit on the head by my partner in a fight. $0 \begin{array}{lllllll}0 & 1 & 3 & 4 & 5 & 7\end{array}$ 10. My partner passed out from being hit on the head in a fight with me.

11. I called my partner fat or ugly.

$0 \begin{array}{lllllll}0 & 2 & 3 & 4 & 5 & 6 & 7\end{array}$

12. My partner called me fat or ugly.

13. I punched or hit my partner with something that could hurt.

14. My partner did this to me. 


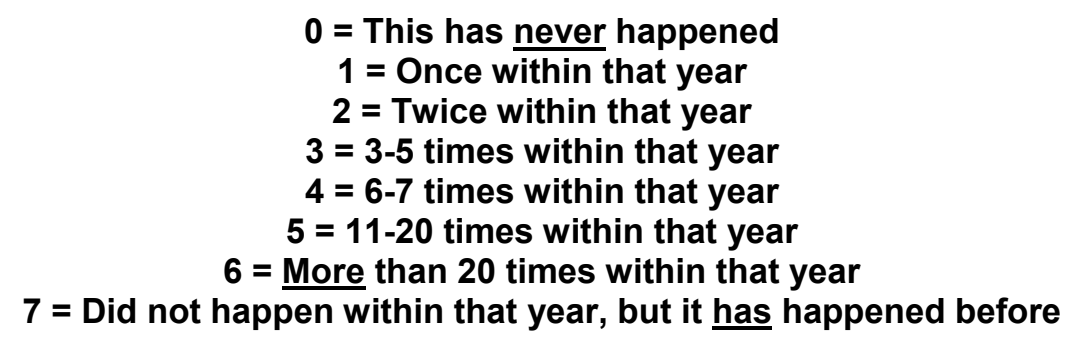

17. I went to a doctor because of a fight with my partner.

$0 \begin{array}{lllllll}0 & 2 & 3 & 4 & 5 & 6 & 7\end{array}$

18. My partner went to a doctor because of a fight with me.

$\begin{array}{llllllll}0 & 1 & 2 & 3 & 4 & 5 & 6 & 7\end{array}$

19. I choked my partner.

$0 \begin{array}{lllllll}0 & 1 & 3 & 4 & 5 & 6 & 7\end{array}$

20. My partner did this to me.

$0 \begin{array}{lllllll}0 & 1 & 3 & 4 & 5 & 6 & 7\end{array}$

21. I shouted or yelled at my partner.

$0 \begin{array}{lllllll}0 & 2 & 3 & 4 & 5 & 6 & 7\end{array}$

22. My partner did this to me.

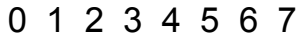

23. I slammed my partner against a wall.

$0 \begin{array}{lllllll}0 & 1 & 3 & 4 & 5 & 6 & 7\end{array}$

24. My partner did this to me.

$0 \begin{array}{lllllll}0 & 2 & 3 & 4 & 5 & 6 & 7\end{array}$

25. I said I was sure we could work out a problem.

26. My partner was sure we could work it out.

0122345567

$0 \begin{array}{lllllll}0 & 2 & 3 & 4 & 5 & 6 & 7\end{array}$

27. I needed to see a doctor because of a fight with my partner, but I didn't.

012334567

28. My partner needed to see a doctor because of a fight with me, but didn't.

$0 \begin{array}{lllllll} & 2 & 3 & 4 & 5 & 6 & 7\end{array}$

29. I destroyed something belonging to my partner.

$0 \begin{array}{lllllll}0 & 2 & 3 & 4 & 5 & 6 & 7\end{array}$

30. My partner did this to me.

$0 \begin{array}{lllllll}0 & 1 & 3 & 4 & 5 & 6 & 7\end{array}$

31. I went to a doctor because of a fight with my partner.

$0 \begin{array}{lllllll}0 & 1 & 3 & 4 & 5 & 6 & 7\end{array}$

32. My partner went to a doctor because of a fight with me.

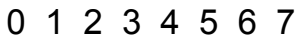

33. I choked my partner.

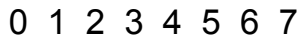

34. My partner did this to me.

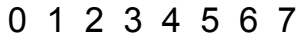

35. I shouted or yelled at my partner.

$0 \begin{array}{lllllll}0 & 1 & 3 & 4 & 5 & 6 & 7\end{array}$

36. My partner did this to me.

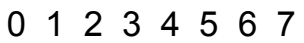

37. I slammed my partner against a wall. $\quad 0 \begin{array}{lllllll}2 & 3456\end{array}$ 38. My partner did this to me.

$0 \begin{array}{lllllll}0 & 2 & 3 & 4 & 5 & 6 & 7\end{array}$

39. I said I was sure we could work out a problem.

$0 \begin{array}{lllllll}0 & 2 & 3 & 4 & 5 & 6 & 7\end{array}$

40. My partner was sure we could work it out.

$0 \begin{array}{lllllll}0 & 2 & 3 & 4 & 5 & 6 & 7\end{array}$

41. I needed to see a doctor because of a fight with my partner, but I didn't.

$0 \begin{array}{lllllll}0 & 2 & 3 & 4 & 5 & 6 & 7\end{array}$

42. My partner needed to see a doctor because of a fight with me, but didn't.

43. I beat up my partner.

$0 \begin{array}{lllllll}0 & 1 & 2 & 3 & 4 & 5 & 6\end{array}$

44. My partner did this to me.

$0 \begin{array}{lllllll}0 & 1 & 3 & 4 & 5 & 6 & 7\end{array}$ 


\section{$0=$ This has never happened \\ $1=$ Once within that year \\ $2=$ Twice within that year \\ $3=3-5$ times within that year \\ $4=6-7$ times within that year \\ $5=11-20$ times within that year \\ $6=$ More than 20 times within that year \\ 7 = Did not happen within that year, but it has happened before}

45. I grabbed my partner.

$0 \begin{array}{lllllll}0 & 1 & 3 & 4 & 5 & 6 & 7\end{array}$

46. My partner did this to me.

47. I used force (like hitting, holding down, or using a weapon) to make my partner have sex.

48. My partner did this to me.

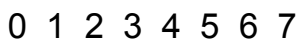

$\begin{array}{llllllll}0 & 1 & 2 & 3 & 4 & 5 & 6 & 7\end{array}$

49. I stomped out of the room or house or yard during a disagreement.

50. My partner did this to me.

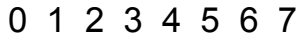

$0 \begin{array}{lllllll}0 & 2 & 3 & 4 & 5 & 6 & 7\end{array}$

51. I insisted on sex when my partner did not want to (but did not use physical force).

52. My partner did this to me.

$0 \begin{array}{lllllll}0 & 1 & 3 & 4 & 5 & 6 & 7\end{array}$

53. I slapped my partner.

$0 \begin{array}{lllllll}0 & 2 & 3 & 4 & 5 & 6 & 7\end{array}$

54. My partner did this to me.

0122345667

55. I had a broken bone from a fight with my partner.

$0 \begin{array}{lllllll}0 & 1 & 2 & 3 & 4 & 5 & 6\end{array}$

56. My partner had a broken bone from a fight with me.

0122345667

(

0122345567

57. I used threats to make my partner have oral or anal sex.

58. My partner did this to me.

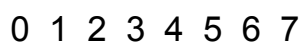

0122345667

59. I suggested a compromise to a disagreement.

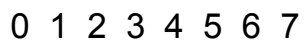

60. My partner did this to me.

$0 \begin{array}{lllllll}0 & 1 & 3 & 4 & 5 & 6 & 7\end{array}$

61. I burned or scalded my partner on purpose.

62. My partner did this to me.

$0 \begin{array}{lllllll}0 & 1 & 2 & 3 & 4 & 5 & 6\end{array}$

$0 \begin{array}{lllllll}0 & 1 & 2 & 3 & 4 & 5 & 6\end{array}$

63. I insisted my partner have oral or anal sex (but did not use physical force).

64. My partner did this to me.

$0 \begin{array}{lllllll}0 & 1 & 2 & 4 & 5 & 6 & 7\end{array}$

64. My partner did this to me.

$0 \begin{array}{llllll}0 & 1 & 3 & 4 & 5 & 67\end{array}$

65. I accused my partner of being a lousy lover.

66. My partner accused me of this.

$0 \begin{array}{lllllll}0 & 2 & 3 & 4 & 5 & 6 & 7\end{array}$

67. I did something to spite my partner.

68. My partner did this to me.

0122345567

69. I threatened to hit or throw something at my partner.

70. My partner did this to me.

$0 \begin{array}{lllllll}0 & 1 & 2 & 4 & 5 & 6 & 7\end{array}$

$0 \begin{array}{lllllll}0 & 1 & 3 & 4 & 5 & 6 & 7\end{array}$

71. I felt physical pain that still hurt the next day because of a fight with my partner. 012345567

72. My partner still felt physical pain the next day because of a fight we had.

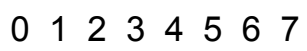

$0 \begin{array}{lllllll}0 & 2 & 3 & 4 & 5 & 6 & 7\end{array}$ 


$$
\begin{aligned}
& 0=\text { This has never happened } \\
& 1=\text { Once within that year } \\
& 2=\text { Twice within that year } \\
& 3=3-5 \text { times within that year } \\
& 4=6-7 \text { times within that year } \\
& 5=11-20 \text { times within that year } \\
& 6=\text { More than } 20 \text { times within that year } \\
& 7=\text { Did not happen within that year, but it has happened before }
\end{aligned}
$$

73. I kicked my partner.

74. My partner did this to me.

75. I used threats to make my partner have sex.

$0 \begin{array}{lllllll}0 & 1 & 2 & 3 & 5 & 6 & 7\end{array}$

76. My partner did this to me.

77. I agreed to try a solution to a disagreement that my partner suggested.

78. My partner agreed to try a solution I suggested. 
Appendix C

Demographic Questionnaire

Age

Predominant Race/Ethnicity:

1. African American

2. Asian American

3. Caucasian

4. Hispanic

5. Other

\section{Educational Level}

1. Bachelor's degree or higher

2. Associate degree

3. Currently in college/Some college (no degree yet)

4. High School diploma (and never enrolled in college)

How long have you been in /were you in your MOST SERIOUS relationship? Years Months

Please categorize your dating history within the last 18 months: (circle all that apply)

1. Dated casually

2. Exclusively dating for six months or less

3. Exclusively dating for more than six months

4. Co-habitating

5. Engaged

6. Married

7. Separated

8. Divorced

9. Remarried

10. Widowed

What best describes your MOST SERIOUS relationship? (circle one)

1. Dating casually

2. Exclusively dating for six months or less

3. Exclusively dating for more than six months

4. Co-habitating

5. Engaged

6. Married

7. Separated

8. Divorced

9. Remarried

10. Not currently in a relationship 
Please describe any cardiovascular illness that you have or have had in the past (e.g., high blood pressure...)

Please list any other medical conditions that you have:

Please list any medications that you are currently taking on a regular basis (prescription or over-the-counter)

Are you a smoker?(circle one) Yes No

If "Yes", how much do you smoke? _Cigarettes/day or packs/day

Family situation for majority of childhood (birth until when you came to college):

1. Lived with biological mother and father

2. Lived with one biological parent and one step-parent

3. Lived with single parent

4. Lived with guardian, grandparents, other family members

5. Adopted

Please indicate the nature of conflict that you witnessed between your parents/guardians in your home: (circle all that apply)

1. No verbal or physical conflict

2. Verbal, but not physical conflict

3. Verbal and physical conflict

4. Physical conflict only

Please specify the nature of the conflict that you witnessed between your parents/guardians: (circle all that apply)

1. Arguing with no physical aggression

2. Minor physical aggression (slapping, pushing, throwing things...)

3. Major physical aggression (punching, threatening with a weapon, kicking...) 


\section{Please indicate the severity of the conflict that you witnessed} between your parents/guardians:

1. No one was ever physically hurt or emotionally scarred

2. Someone was hurt (bruises, cuts, black eyes...) or emotionally scarred (the effects of the conflict interfered with their day-today life or required them to seek counseling)

3. Someone required medical treatment or hospitalization

Please indicate the type of conflict you most often witnessed between your parents/guardians:

1. The male was the aggressor toward the female and the female did not retaliate

2. The female was the aggressor toward the male and the male did not retaliate

3. Both the male and the female exhibited aggression toward one another

\section{Very Important!!!!}

Please indicate you willingness to be considered for participation in phase 2 of this research for additional extra credit and financial incentive by providing the following information: If you wish to remain anonymous, you can provide a first name only.

- Please contact me at the following phone number and/or email address:

- Please do not contact me for a chance to participate in phase 2 of this study 
Appendix D

Participant Discussion Task Instructional Sets

“Mess" Scene

Your roommate is a slob and the apartment is a mess. You always do your share. You ask her to do the dishes because you have a date/friends coming over. You get back home and the place is worse than when you left.

Goal: Get your roommate to agree to clean up the apartment.

Guidelines:

- Try your best to achieve your goal of getting your female roommate to clean the apartment

- Do your best to provide a counter-argument to all of her arguments

- Be persistent until you are told to "stop"

- Do NOT let the roommate "win" the argument 


\section{"Noise" Scene}

You've got to go to bed early tonight because you have a major test first thing in the morning. Your neighbor comes home and turns on the stereo full blast.

Goal: Get your neighbor to agree to turn off the stereo.

\section{Guidelines:}

- Try your best to achieve your goal of getting your neighbor to turn the stereo off

- Do your best to provide a counter-argument to all of her arguments

- Be persistent until you are told to "stop"

- Do NOT let your neighbor "win" the argument 


\section{Appendix $E$ \\ Confederate Discussion Task Instructional Sets \\ “Mess" Scene}

Your roommate is a slob and the apartment is a mess. You always do your share. You ask her to do the dishes because you have a date/friends coming over. You get back home and the place is worse than when you left.

Goal: Get your roommate to agree to clean up the apartment.

Confederate Structured Prompts:

- I do my share, I pick up after myself.

- It's not that bad.

- It's not exactly dust free, but it looks okay.

- I'll get to it later.

- You should have given me more notice.

- I cleaned as much as I could, but I had to go to class.

- I didn't have time.

- I'm busy, l've got to study for an exam.

- I've got things to do, I can't clean the apartment now.

- You mess up the apartment too.

- I get tired of picking up after you.

- They're your friends.

- If it bothers you so much, you do it. 


\section{"Noise" Scene}

You've got to go to bed early tonight because you have

a major test first thing in the morning. Your neighbor comes home and turns on the stereo full blast.

Goal: Get your neighbor to agree to turn off the stereo.

Confederate Structured Prompts:

- I didn't know you were home.

- It wasn't that loud.

- I wasn't playing it that long.

- It's still early.

- You could fall asleep with it on.

- It's a stress release for me and my friends during exams.

- Come on, we won't be playing it that much longer, only a couple of hours.

- We can't hear our music from outside.

- It's my place, I can play music if I choose.

- You play your music real loud/louder.

- At least I have better taste in music.

- Get some earplugs, l'll be glad to get you some cotton if you don't have any. 


\section{Appendix F}

Confederate Reliability Rating Form

1. How confrontational was the female during the discussion?

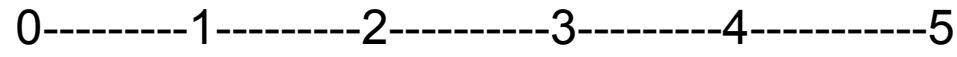

2. How antagonistic was the female during the discussion?<smiles>[3H][Hg]S[C][AlH]O</smiles>

3. How friendly was the female during the discussion?

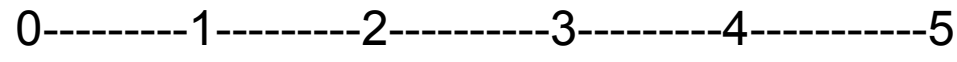

4. How relentless in keeping the dialogue going was the female during the discussion?

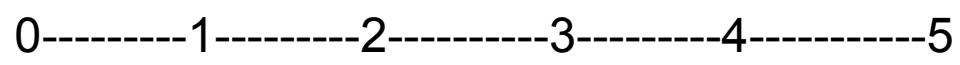

5. How compassionate was the female during the discussion?

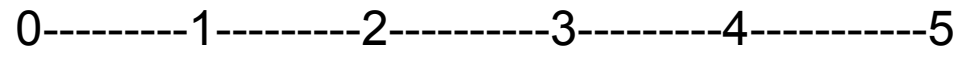




\section{Footnotes}

${ }^{1}$ Throughout this paper the term "aggressive" will be used to denote physical and/or psychological acts of intimate partner abuse. Where "violent is used, physical aggression is being referenced.

${ }^{2}$ There were also no significant order by task interactions for STAXI-2 scores or heart rate reactivity. 